\title{
Overview of Recent Circulation Control Modeling Activities at Cal Poly
}

\author{
David D. Marshall * and Kristina K. Jameson ${ }^{\dagger}$ \\ California Polytechnic State University, San Luis Obispo, CA 93407-0352, USA
}

\begin{abstract}
This paper provides an overview of the Circulation Control modeling research that has been performed, and is still ongoing, at Cal Poly, San Luis Obispo. This work started in 2005 with the interest of applying Circulation Control technologies to advanced aircraft designs. After the initial investigations into this, it was apparent that there was a long history of experimental work in this area to build on, but a number of deficiencies existed in the modeling capabilities. For Circulation Control enabled aircraft, these included: few available tools to accurately model the takeoff and landing performance, the limitations in the standard regulations with respect to takeoff and landing requirements, the inconsistent published results in modeling the aerodynamics of these problems, and the lacking of tools necessary to model the coupling of the propulsion system and the aerodynamics. These were some of the problems that Cal Poly researchers, both students and faculty, identified as avenues of exploration, and these are the areas that have received the majority of the focus since the beginning of this work. This is the work that will be summarized in this
\end{abstract} paper.

\section{Nomenclature}

$\begin{array}{ll}c & \text { Chord length of airfoil } \\ C_{f} & \text { Skin friction coefficient } \\ C_{\ell} & \text { 2D dimensional lift coefficient, }=L^{\prime} /\left(q_{\infty} c\right) \\ C_{L} & \text { 3D lift coefficient, }=L /\left(q_{\infty} S\right) \\ C_{L, \text { max }} & \text { Maximum 3D lift coefficient } \\ C_{\mu} & \text { Blowing coefficient, }=\dot{m}_{\text {slot }} U_{\text {slot }} /\left(q_{\infty} S\right) \\ C_{p} & \text { Pressure coefficient } \\ L & \text { 3D lift force } \\ L^{\prime} & \text { 2D dimensional lift force } \\ n_{o} & \text { Oil index of refraction } \\ q & \text { Dynamic pressure, }=\frac{1}{2} \rho U^{2} \\ S & \text { Reference area for nondimensionalizing force coefficients } \\ U, V & \text { Velocity } \\ \text { Subscripts } & \\ \infty & \text { Conditions at freestream } \\ \text { slot } & \text { Conditions at slot } \\ \text { Conventions } & \\ \text { AMELIA } & \text { Advanced Model for Extreme Lift and Improved Aerocoustics } \\ \text { BFL } & \text { Blanced Field Length } \\ \text { CC } & \text { Circulation Control } \\ \text { CCA } & \text { Circulation Control Airfoil } \\ \text { CCW } & \text { Circulation Control Wing } \\ \text { CESTOL } & \text { Cruise Efficient Short Takeoff and Landing } \\ \text { CST } & \text { Class/Shape Transformation } \\ \text { ESTOL } & \text { Extremely Short Takeoff and Landing } \\ \text { FISF } & \text { Fringe-Image Skin Friction } \\ \end{array}$

\footnotetext{
${ }^{*}$ Associate Professor, Aerospace Engineering Department, Senior Member AIAA.

${ }^{\dagger}$ Assistant Professor, Aerospace Engineering Department, Member AIAA.
} 
GACC

NFAC

NLEVM

OEI

RANS

SARC

TPS

Symbols

$\Delta s$

$\lambda$

$\mu_{o}$

$\rho$

$\tau_{w}$

$\theta_{r}$
General Aviation Circulation Control airfoil

National Full-Scale Aerodynamics Complex

Non-Linear Eddy Viscosity Model

One Engine Inoperative

Reynolds Averaged Navier-Stokes

Spalart-Allmaras Turbulence Model with Rotational and Curvature Corrections

Turbofan Propulsion Simulator

Spacing distance on oil fringes

Wavelength of the light source

Oil viscosity

Density

Wall shear stress

Light refraction angle through the air-oil interface

\section{Introduction}

$\mathrm{T}$ HE research and use of Circulation Control (CC) technologies since as far back as the 1930's. Englar ${ }^{1}$ provides an excellent summary of the history and uses of CC technologies. While a significant amount of the research has been in traditional aerospace disciplines such as fixed wing and rotary wing applications, there have been some interesting applications to a wide variety of disciplines such as heat exchangers, ${ }^{2}$ cars and trucks, ${ }^{3}$ commercial and sport vehicles, ${ }^{4}$ and an number of other intriguing applications. ${ }^{5,6}$ There has even been research into using CC technologies for flight controls. ${ }^{7} \mathrm{CC}$ technologies have even been studied to be used to reduce the rotor downforce on the $\mathrm{V}-22^{8}$. Recently the noise associated with $\mathrm{CC}$ technologies has been studied ${ }^{9,10}$ in order to better characterize the acoustic effects of CC technologies. Friedman et al. ${ }^{11}$ studied the Mach number variation of the CCA performance, and found that the airfoil type played a significant role. Compressibility effects for elliptic airfoils could be account for with the standard Prandtl-Glauert compressibility correction factor. However, for airfoils with flaps, the performance variation was strongly dependent on a critical blowing coefficient. Below a value and little lift improvement occurred, and above it there was a significant lift improvement. This critical blowing coefficient increased with Mach number.

There have been a number of experimental studies into CC technologies that provide significant insight into the flow physics as well as provide valuable data for computational comparison. ${ }^{1,12-17}$ Jones et al. ${ }^{18}$ studied the General Aviation Circulation Control airfoil with a circular trailing edge and a dual radius flap. They characterized the flow field using PIV and presented velocity profiles, Reynolds shear stress profiles, and turbulence intensity contours. They also presented pressure coefficients and lift variations. There is a number of excellent quantities to use to compare CFD results against. Lee-Rausch et al. ${ }^{19}$ presented another set of experimental data for the same GACC airfoil. In addition they presented a comparison against a number of CFD codes and variations of the codes. They found that lift coefficient is over-predicted by the CFD schemes, and that there was little variation between the codes. This dataset is another valuable validation dataset for $2 \mathrm{D}$ CC flows. Englar et al. ${ }^{20}$ performed a $2 \mathrm{D}$ study of a CCA configuration with a dual radius flap. In this work, the CFD results were used to analyze the experimental data to determine corrections terms for the tunnel effects. The authors have test data from two separate tunnels and have a database of test results that can be used for future CFD validation studies. While there are a number of excellent 2D experimental datasets available for CFD validation, the same is not true for 3D experimental data. One dataset that focused on the low blowing coefficients, with $C_{\mu}<0.06$, is by Pfingsten and Radespiel. ${ }^{21}$ The present flow field data, boundary layer profiles, surface pressure distributions and force measurements.

There are a number of papers in the past few years presenting computational studies of CC technologies. Most of them have focus on 2D studies ${ }^{22-31}$ where the turbulence modeling is the most studied idea. Min et al. ${ }^{32}$ also presented some evidence that including the plenum region for the slot flow improved the quality of their flow results, but not the overall airfoil performance prediction. Fasel et al. ${ }^{33}$ presented DNS as well as a traditional RANS results for Coanda wall jets.

Swanson and Rumsey ${ }^{34}$ present a comparison of several turbulence models on several CC airfoils. They showed that the ability to capture the correct slot flow behavior was strongly coupled to the mesh resolution used in that region. Overall the turbulence model behaviors (and the ability to accurate capture the flow field) were not consistent and showed significant sensitivity to the numerics involved. Lee-Rausch et al. ${ }^{19}$ presented a thorough analysis of several CFD codes and a few CCA shapes. They reported less variation in results between CFD codes, and they also reported significant differences between the CFD solutions and the experimental data. 


\section{Circulation Control Technologies Applied to Aircraft Design}

The Circulation Control, CC, work at Cal Poly started as an applied aerodynamics and aircraft design project by de la Montanya and Marshall. ${ }^{35,36}$ The task was to investigate the integration of CC technologies into an aircraft design. This preliminary work studied how to model the dual radius flap design and integrate the results into an aircraft design. What resulted from this work was an understanding that there are significant difficulties in modeling the flows using CFD, the need for improved takeoff and landing modeling techniques, and the difficulties in satisfying federal aviation regulations concerning aircraft performance during takeoff and landing.

\section{A. Takeoff and Landing Modeling}

Using the equations for takeoff and landing approximations, such as landing distance and balanced field length (BFL), found in standard aircraft design textbooks such as Torenbeeks ${ }^{37}$ is not appropriate for these applications. The coupling between the propulsion and aerodynamics is non-standard, and many of the assumptions that went into the modeling the individual technologies (i.e., the propulsion system model or the aerodynamics model) are not valid for CC applications.

Englar et al. ${ }^{38,39}$ developed techniques for takeoff and landing modeling of CC enabled aircraft. They used a Boeing 737-100 as the baseline aircraft and applied increments to the aerodynamics performance to account for the lift augmentation from the CC technologies. Without performance data for the enhanced configuration, semi-empirical methods were used to determine the new aerodynamics performance characteristics. To model the impact of the CC technologies on the engine characteristics, an assumed engine model (since the actual engine performance deck was not available) with engine bleed was created. A direct correlation between amount of airflow bled off the fan stage and the amount of thrust loss. Note that there was no data available in their experimental or computational analysis to address the coupling between the aerodynamics and the propulsion system.

In order to determine the takeoff and landing performance, the equations of motion were numerically integrated to determine the distances. To handle the dependency between the instantaneous stall speed and the blowing coefficient, an iterative process was developed. In traditional aircraft performance analysis, the stall speed is fixed since the maximum lift coefficient is constant for the aircraft. With the added complexity of CC technologies, this is no longer true. While the details of the iteration process were not provided, it appears that at each point in the ground roll the instantaneous $C_{L, \max }$ is determined from the given $q_{\infty}$, which yields an instantaneous $C_{\mu}$. This $C_{L \text {, max }}$ can then used to find the instantaneous $V_{\text {stall }}$. This velocity can then be compared to instantaneous velocity to determine whether the rotation speed has been reached. While this technique is true to the takeoff modeling specifications is the Federal Aviation Regulations, FAR $25,{ }^{40}$ it is a time-consuming process if the aerodynamics data is not precomputed. Their results show a reduction in takeoff distance of between $25 \%$ and $75 \%$. Similarly, for landing distance a reduction of $50 \%$ to $75 \%$ was obtained.

In an attempt to minimize the induced drag associated with CCW, Alley et al. ${ }^{41}$ used an optimization method based on the steepest descent technique to find the mass flow rate variation across the slots that achieve an elliptic lift distribution. They achieve a $25 \%$ reduction in induced drag and an overall drag reduction of $32 \%$. The authors do recognize the significant challenge implementing this on an actual aircraft since many flight conditions would need to be analyzed, and a different blowing coefficient variation for flight condition will most likely result. They also suggest a combined spanwise blowing variation and twist distribution in order to reduced the amount of twist required to obtain an elliptic loading of the wing.

One recent approach to address the coupling between the aerodynamics and the propulsion system was presented by Bobbitt and Margason ${ }^{42}$ for modeling upper surface blowing configurations. They modeled takeoff and landing with curve fits to performance data of the propulsion and aerodynamic systems. Additional curve fits were required to obtain the lift coefficient versus blowing coefficient variation. Specifically, they used quadratic polynomial variations of such as

$$
C_{L, \max }=a_{1}+a_{2} C_{\mu}+a_{3} C_{\mu}^{2}
$$

What results is a variation of the maximum lift coefficient with respect to the blowing coefficient. This can then be used to determine rotation velocity for takeoff. While this does solve the problem of having a non-constant stall speed during takeoff, there are no assurances that the variation follows a quadratic variation even for small variations of blowing coefficients. In typical operations a fixed mass flow rate from the slots occurs since bleading from the engine or even dedicated air sources should have little variation with freestream speed. Thus, as the freestream speed increases, $C_{\mu}$ will decrease. A reduction in $C_{\mu}$ means that the Coanda effect will be reduced and the stall speed is reducing. Thus near rotation, when the plane should be operating near the stall speed to obtain maximum lift, the stall speed and current speed are rapidly approaching each other. This has the possibility of producing a very nonlinear variation. Their work demonstrated a significant reduction in takeoff and landing distances.

In an attempt to achieve a better model of the coupled propulsion and aerodynamic systems, Cal Poly developed an improved modeling technique using Gaussian Process Metamodeling ${ }^{43,44}$ and applying it to a typical ESTOL 
aircraft design with less than 100 passenger capacity. ${ }^{45,46}$ Figure 1 shows a block diagram of the code used for this analysis. The code integrated the equations of motion for the aircraft trajectory through ground roll and climb out (or braking) to satisfy the balanced field length criteria of clearing an obstacle (either $35 \mathrm{ft}$ or $50 \mathrm{ft}$ depending on civilian or military criteria) or decelerating to a full stop. The propulsion model was a simple thrust equation based on the freestream velocity. Later work by Waters et al. ${ }^{47}$ demonstrated that more advanced modeling of the propulsion system provides only marginal improvements to the fidelity of the thrust variation during takeoff.

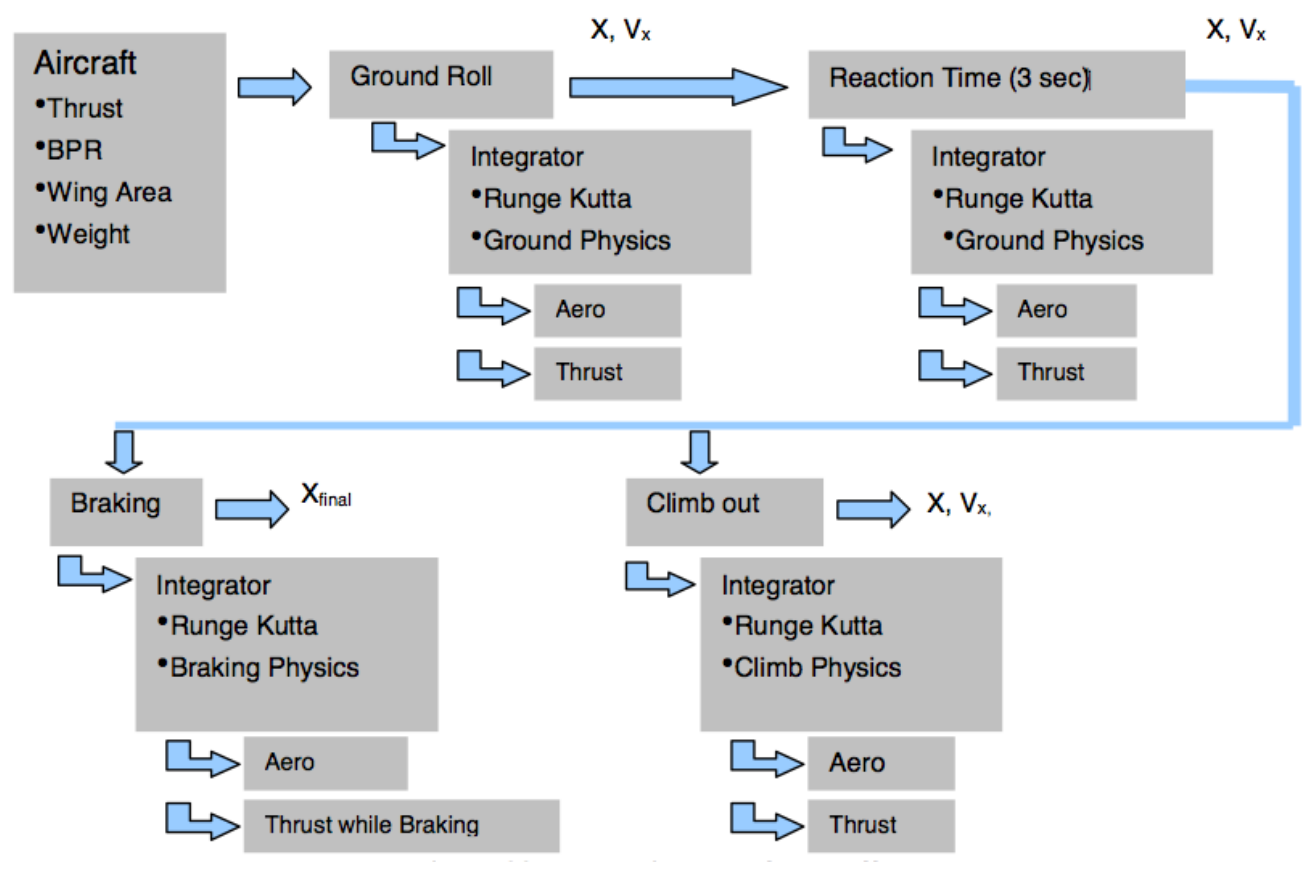

Figure 1. Block diagram of the balanced field length code used to determine the takeoff characteristics of a notional aircraft using circulation control technologies and coupled propulsion system and aerodynamics models.

The aerodynamics were modeled by performing around 40 CFD simulations of various flight conditions throughout the takeoff regime. It was assumed that there were 4 main variables to defining the parameter space associated with the aerodynamics; they were angle of attack, freestream Mach number, mass flow rate from the slot, and dual radius flap deflection angle. The 40 CFD simulations were determined using a full random sampling of the parameter space. The results were stored in a MySQL database, and a Gaussian Process Metamodel was used to model the aerodynamics. This metamodeling was based on the work by Rasmussen ${ }^{48}$ with the hyper-parameters chosen to minimize the log likelihood.

For aircraft with $\mathrm{CC}$ technologies, determining the rotation speed becomes a complicated task that is strongly dependent on the freestream speed as discussed above. Instead of explicitly tying the rotation speed to $C_{L, \max }$, an alternative criteria was developed. It is assumed that the rotation should occur when the lift generated is some fraction of the lift at stall, which is equivalent to the weight, $W$, of the aircraft and when the lift coefficient is $90 \%$ of the stall lift coefficient. Utilizing the following equations, a criteria for rotation can be determined that is based on the lift generated.

$$
\begin{aligned}
k & =\frac{L_{r}}{L_{\text {stall }}}=\frac{L_{r}}{W} \\
1.05 & =\frac{V_{r}}{V_{\text {stall }}} \\
0.9 & =\frac{C_{L, r}}{C_{L, \text { max }}}=\frac{L_{r}\left(\frac{\rho}{2} V_{r}^{2}\right) S}{L_{\text {stall }}\left(\frac{\rho}{2} V_{\text {stall }}^{2}\right) S} \\
& =\left(\frac{L_{r}}{L_{\text {stall }}}\right)\left(\frac{V_{r}}{V_{\text {stall }}}\right)^{2}
\end{aligned}
$$

From this analysis, rotation should occur when the lift is approximately $82 \%$ of the aircraft weight. This criteria worked well for two validation cases, a McDonnell Douglas DC-9 and a Boeing 747-400. Details of the comparison can be found in Reference 45. 
The BFL analysis was done on a notional STOL transport aircraft with a thrust of 130,000 lbs, wing area of 2,200 $\mathrm{ft}^{2}$, and a weight of 230,000 lbs. An assumed $20 \%$ reduction of mass flow from the engines was assumed available to be diverted to the CCW slots.

Figure 2 shows the varation of BFL with flap deflections for a number of mass flow rates. For these simulations a fixed mass flow rate is bled from the engine which results in $C_{\mu}$ reducing throughout the ground roll (since $q_{\infty}$ is increasing). Notice that for the variety of mass flow rates, there is an optimal flap deflection angle that is between $60^{\circ}$ and $65^{\circ}$. For a specific mass flow rate there is a large variation in balanced field length (as much as $20 \%$ variation at the lowest slot mass flow rate).

There is also a diminishing return as the slot mass flow rate increases. The cases that were run increased the slot mass flow rate by a constant amount, but there is little improvement in the BFL between the final two mass flow rates. Note that the improvement between the lowest and the highest mass flow rates cases is $20 \%$ (from $3000 \mathrm{ft}$ down to $2400 \mathrm{ft}$ ).

This work also investigated techniques to further improve the BFL performance of this aircraft by varying the slot mass flow rate and fixing the flap deflection angle at the optimal setting of $64^{\circ}$. Two techniques were

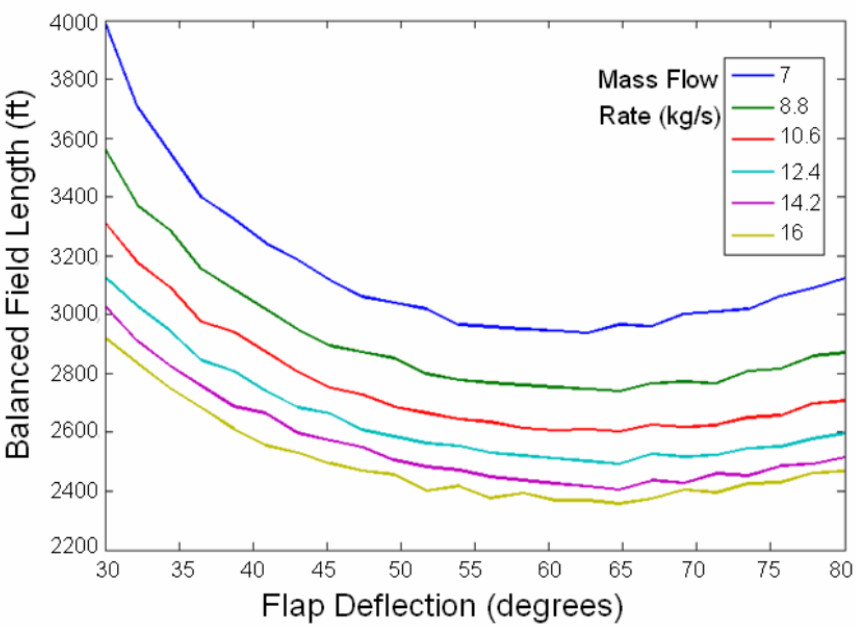

Figure 2. Balanced Field Length results for coupled aerodynamics and propulsion system for a variety of slot mass flow rates and flap deflections. examined: one where the slot mass flow rate is activated once the aircraft speed was $100 \mathrm{ft} / \mathrm{s}$ and one where the slot mass flow rate was increased from zero to the final mass flow rate of $20 \mathrm{~kg} / \mathrm{s}$ quadratically. Figure 3 shows the lift coefficient, drag coefficient, and the lift-to-drag ratio for these cases. Notice that the lift-to-drag ratio is much higher for the step increase in slot mass flow rate. This means that there is less drag being produced as the airplane travels during ground roll. This is due to the lower induced drag experienced because of a lower lift coefficient for this case.

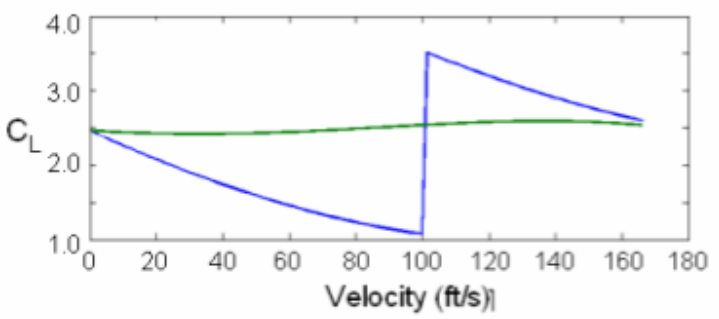

(a) Lift Coefficient

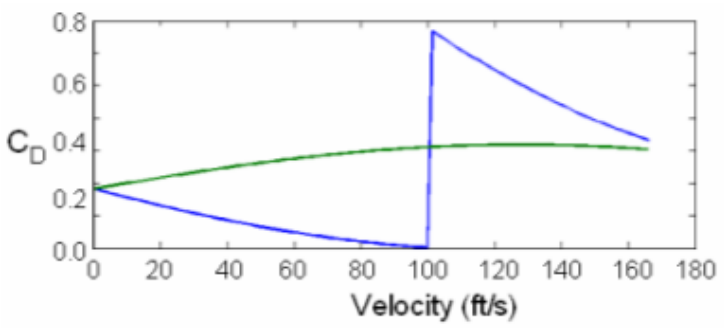

(b) Drag Coefficient

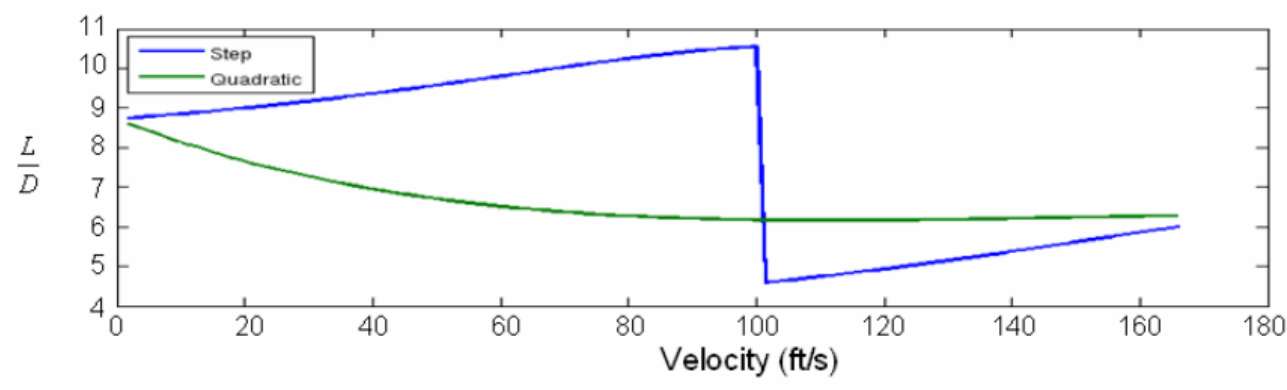

(c) Lift over Drag

Figure 3. Aerodynamic performance as the slot mass flow rate is varied either gradually or instantaneously from no mass flow rate to the maximum mass flow rate of $20 \mathrm{~kg} / \mathrm{s}$.

Tables 1 and 2 shows a summary of results for a variety slot mass flow rate schemes. Comparing the quadratic cases with the step cases, it is clear that the step cases produce a lower takeoff distance as well as a lower BFL. While the quadratic variation did produce a decrease in both distances, the decrease was minimal (a maximum of $3.2 \%$ ). 
Turning on the mass flow rate later in the ground roll further decreased both distances. A maximum improvement is $6.2 \%$ and $8.7 \%$ for the takeoff distance and BFL, respectively. Clearly there is a practical limit in this since the blowing must be activated before rotation, but it is beneficial to delay the activation of the slot mass flow as long as practical.

Table 1. Takeoff distance results for two slot mass flow rates with three different mass flow variations during ground roll. The percentage results are relative to the constant blowing case.

\begin{tabular}{rcccccccc} 
& \multicolumn{2}{c}{ Constant } & \multicolumn{2}{c}{ Quadratic } & \multicolumn{2}{c}{$100 \mathrm{ft} / \mathrm{s}$} & \multicolumn{2}{c}{$180 \mathrm{ft} / \mathrm{s}$} \\
Mass Flow Rate & Distance & Decrease & Distance & Decrease & Distance & Decrease & Distance & Decrease \\
\hline $10 \mathrm{~kg} / \mathrm{s}$ & $2536 \mathrm{ft}$ & $0 \%$ & $2515 \mathrm{ft}$ & $0.83 \%$ & $2512 \mathrm{ft}$ & $0.95 \%$ & $2479 \mathrm{ft}$ & $2.25 \%$ \\
$20 \mathrm{~kg} / \mathrm{s}$ & $2205 \mathrm{ft}$ & $0 \%$ & $2157 \mathrm{ft}$ & $2.18 \%$ & $2191 \mathrm{ft}$ & $0.63 \%$ & $2068 \mathrm{ft}$ & $6.21 \%$
\end{tabular}

Table 2. BFL distance results for two slot mass flow rates with three different mass flow variations during ground roll. The percentage results are relative to the constant blowing case.

\begin{tabular}{rcccccccc} 
& \multicolumn{2}{c}{ Constant } & \multicolumn{2}{c}{ Quadratic } & \multicolumn{2}{c}{$100 \mathrm{ft} / \mathrm{s}$} & \multicolumn{2}{c}{$180 \mathrm{ft} / \mathrm{s}$} \\
Mass Flow Rate & Distance & Decrease & Distance & Decrease & Distance & Decrease & Distance & Decrease \\
\hline $10 \mathrm{~kg} / \mathrm{s}$ & $2808 \mathrm{ft}$ & $0 \%$ & $2775 \mathrm{ft}$ & $1.18 \%$ & $2776 \mathrm{ft}$ & $1.14 \%$ & $2692 \mathrm{ft}$ & $4.13 \%$ \\
$20 \mathrm{~kg} / \mathrm{s}$ & $2436 \mathrm{ft}$ & $0 \%$ & $2357 \mathrm{ft}$ & $3.24 \%$ & $2395 \mathrm{ft}$ & $1.68 \%$ & $2225 \mathrm{ft}$ & $8.66 \%$
\end{tabular}

\section{B. Federal Aviation Regulations}

With the inclusion of circulation control technology on aircraft, there appears to be some issues related to the BFL determination as specified in FAR 25. ${ }^{40}$ One is the stall speed determination and another is the one engine inoperative, OEI, condition.

\section{Stall Speed and Maximum Lift Coefficient}

For typical aircraft, the stall speed can be deterimined from the simple equation

$$
V_{\text {stall }}=\sqrt{\frac{2 W}{\rho C_{L, \max } S}}
$$

However, this assumes that the maximum lift coefficient for the aircraft is constant throughout the takeoff trajectory. For CC enabled aircraft this is not the case, as mentioned above. It would be extremely difficult to maintain a constant blowing coefficient since the freestream dynamic pressure is constantly changing. This would require a continuous variation in the slot mass flow rate, and keeping those two parameters in synch would be a significant challenge. With the slot blowing coefficient is constantly varying, the lift curve will also vary which means that the stall speed is constantly varying. For performance analysis, alternative techniques can be used such as those mentioned above. For airplane operations, this issue will most likely also need to be addressed.

\section{One Engine Inoperative Condition}

For determination of the balanced field length, the one engine out condition must be simulation. This condition is supposed to be the loss of the most critical engine. For aircraft with circulation control technologies, determining the most critical engine is a more complicated process. Some aircraft might use dedicated compressors to supply the mass flow for the slots, while some might bleed air from a stage in the engine. With this in mind, the loss of an engine might (or might not) impact the aerodynamics as well as the available thrust. On top of this, the air supply feeding the slots might (or might not) be cross-ducted. It is anticipated that determining the OEI condition could be orders of magnitude more complicated because of the large number of additional combinations that must be determined.

Assuming that the OEI condition impacts the slot mass flow rate, then a number of situations could occur. If there is cross-ducting then the mass flow rate through the slots of both wings will be reduced, the blowing coefficient will then be reduced, and there will be a reduction in lift. Without cross-ducting then only one wing will experience 
a reduced mass flow rate, and there will be only one wing with a reduced lift. This will result in a possibly significant rolling moment that will need to be addressed.

Another issue associated with the use of $\mathrm{CC}$ technologies on aircraft arises if it is used for flight control, such as discussed in reference 7 . This could be used for roll control by varying $C_{\mu}$ for the left and right sides; it could be used for pitch control by changing $C_{\mu}$ on both wings (however this will change the lift from the wings) or by using $\mathrm{CC}$ on the tail; and it could be used for yaw control by using $\mathrm{CC}$ on the vertical control surfaces. These situations will also need to be analyzed in the OEI analysis.

One additional note about the CCW is that there is a larger negative pitching moment from the wing compared to a traditional wing. This is mainly caused by the large amounts of lift being generated by the aft end of the wing (around and after the rear slots). This moment needs to be balanced by a larger than typical tail (or some other empannage configuration). It has also been proposed during the preliminary design process of some work at Cal Poly that the tail size can be reduced by using CCW on the tail.

\section{Current Efforts to Improve Modeling Techniques}

\section{A. Turbulence Modeling}

McGowan et al. ${ }^{24}$ performed a comparison of two $k-\zeta$ turbulence models (one fully turbulent ${ }^{49}$ and one with a turbulence transition ${ }^{50}$ ) and also the standard $k-\omega$ model. ${ }^{51}$ Their results indicate that the standard two-equation turbulence models have a difficult time capturing the complicated flow physics associated with the high-speed jet from the slot. This impacts the pressure distribution over the entire airfoil by over predicting the lower surface pressure and under predicting the upper surface pressure. What results is a drastic over-prediction of lift. This effect increases as the $C_{\mu}$ increases. They found limited success with the inclusion of a turbulence transition model and with laminar flow specified for the cavity of the airfoil. Simply making the cavity region turbulent had a significantly negative impact on the pressure distribution over the entire airfoil. This suggests that there is a need for additional work to improve the modeling of CC flows.

One improvement to the standard turbulence models that has seen limited success in modeling CC airfoils is the Spalart-Allmaras one-equation turbulence (SARC) model with rotation and curvature corrections. ${ }^{52}$ Swanson et al. ${ }^{53}$ showed that reasonable results could be obtained with the curvature corrections. However, this was only obtained with an extremely high value for one of the model constants, $c_{r 3}$ was 9.6 while typical values are between 0.6 and 1 . What this extremely high value of $c_{r 3}$ did was reduce the turbulence kinetic energy in the Coanda flow region.

The current turbulence work being investigated by Storm and Marshall ${ }^{54}$ is focused on implementing Durbin's $v^{2}-f$ turbulence model. ${ }^{55}$ While the standard model showed little improvement, the addition of a non-linear eddy viscosity model (NLEVM) by Petterson Rief ${ }^{56}$ and streamline curvature corrections ${ }^{57}$ showed a marked improvement in the predictive capabilities of the RANS solver. Figure 4 shows preliminary results for the General Aviation Circulation Control (GACC) airfoil. Experimental data from Jones et al. ${ }^{18}$ and Lee-Rausch et al. ${ }^{19}$ is presented along with computational results from Lee-Rausch et al. The results from Storm and Marshall are for a number of typical turbulence models, $k-\varepsilon, k-\omega$, and SA, all of which are standard FLUENT models. Those results are typical of other research found using the same turbu-

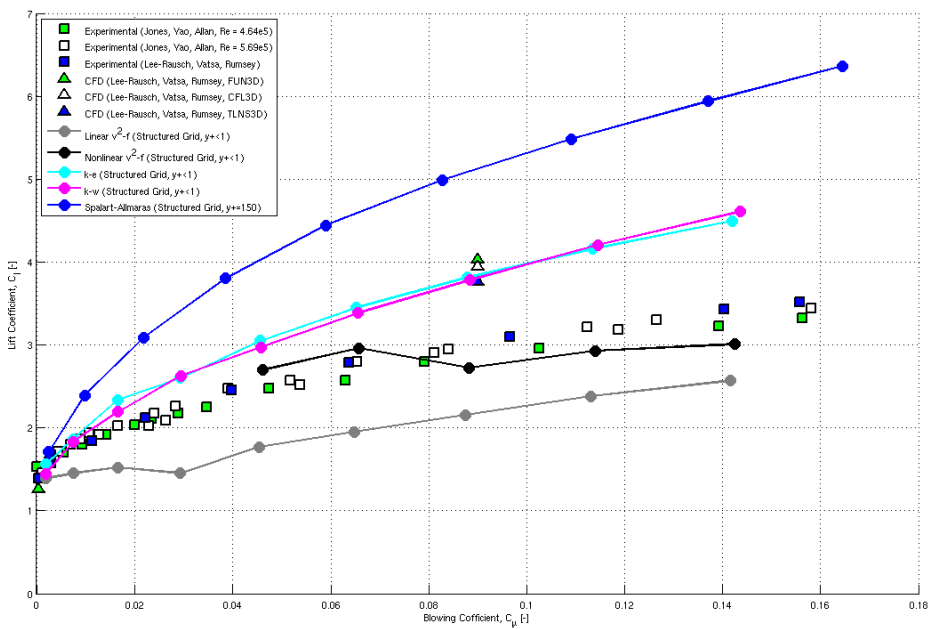

Figure 4. Preliminary results from a turbulence model study on the GACC airfoil compared to a number of experimental and computational results from references 18 and 19 . lence models. In addition, Storm and Marshall implemented a $v^{2}-f$ model with a linear eddy viscosity model in FLUENT using User Defined Functions. This turbulence model under-predicts the lift coefficient variation while all other models over-predict this. The cause for this is still under investigation. Storm and Marshall also implemented a $v^{2}-f$ model with a non-linear eddy 
viscosity model mentioned above. Results from this model are significantly improved compared to all other cases. In the future the curvature correction method presented above will be implemented.

\section{B. Impact of Flap Shape}

Golden and Marshall ${ }^{58}$ are investigating the impact that flap shape has on the circulation control airfoil performance. Two different flap shapes are being studied. One is the dual radius flap which is the standard type that Englar and Huson presented. ${ }^{59}$ The surface of the dual radius flap has a discontinuity in the curvature where the surface radius discretely changes from the smaller radius to the larger radius. The flaps are referred to as the DR class. The other flap shape using the same smaller radius curve to start, but instead of the discontinuous change in curvature, the radius of curvature varies smoothly until the end of the flap. The radius variation is a cubic variation with the radius and the slope of the radius variation set at both ends of the variation. These flaps are referred to as the PR class. To complete the naming convention of the flaps, a 2-digit number is appended to the class that represents length of the flap in percent chord. Figure 5 shows three different pairs of flaps. The 16 variation has a length that is $16 \%$ of the chord, and similarly for the 19 and the 22 variation. The motivation for the PR class of flaps is to eliminate the curvature

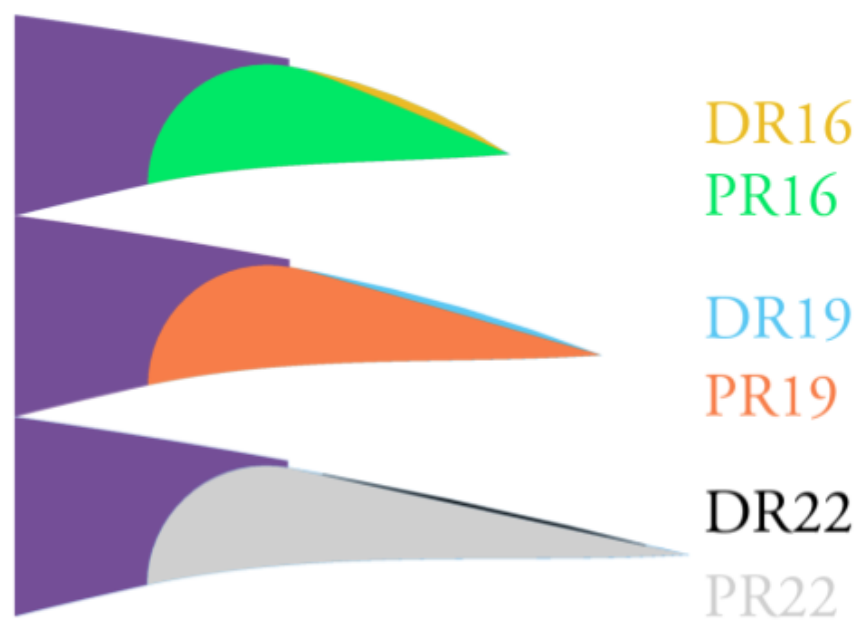

Figure 5. Various flap shapes to be studied. The two classes of flaps are dual radius and prescribed radius. Various flap lengths are shown. discontinuity and determine the performance differences that arise. It is hypothesized that the smooth variation is curvature will be less likely to cause the Coanda flow to separate. Notice that the resulting PR flap is flatter the the same length DR flap. The shorter the flap, the more pronounced the difference. Reference 58 has more details on this work.

Figure 6 shows the streamlines and Mach contours for a flow over an airfoil with a prescribed radius flap, PR16, and a dual radius flap, DR16. The angle of attack for this flow is $0^{\circ}$ and the flap deflection angle is $60^{\circ}$. For these two flows, there is little difference between the two flows. Both show the extreme deflection of the streamlines caused by the CC slot flow.

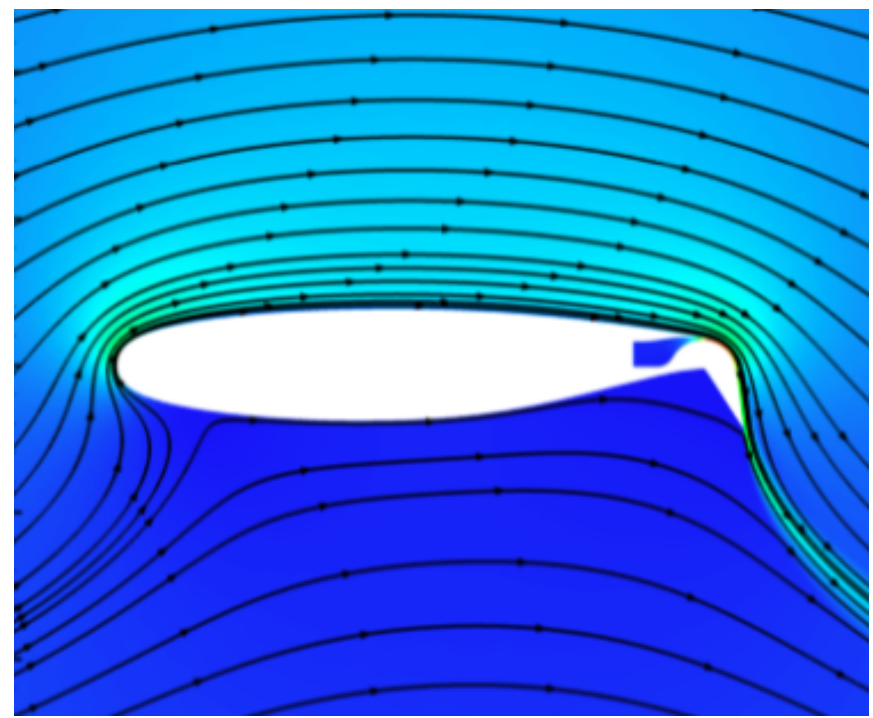

(a) Prescribed Radius

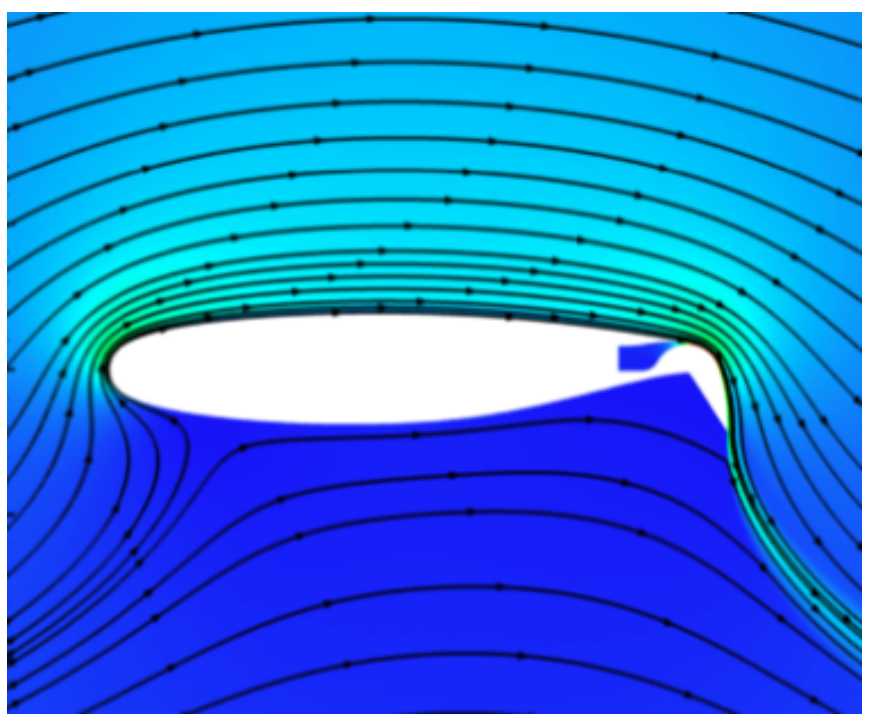

(b) Dual Radius

Figure 6. The streamlines and Mach contours for the two class of flap shapes. The specific shape is the 16 series.

Figure 7 shows the aerodynamic performance of a variety of flap shapes. The drag polars for a wide variety of flap shapes are very similar, with the DR16 showing the most significant difference. Each flap shape was analyzed at the same 3 angles of attack, so the DR16 shows an increase in both lift and drag compared to other shapes. Examining 
the $L / D$ for the same flap shapes show that there is a significant difference between shapes. The DR16 is actually the lowest performing shape (by almost $10 \%$ compared to the best performer PR19). It is also worth noting that the PR class of shapes perform slightly better than the DR class. The significance of this difference is still under investigation. It is planned to have more cases to better characterize the drag polar and the $L / D$ performance.

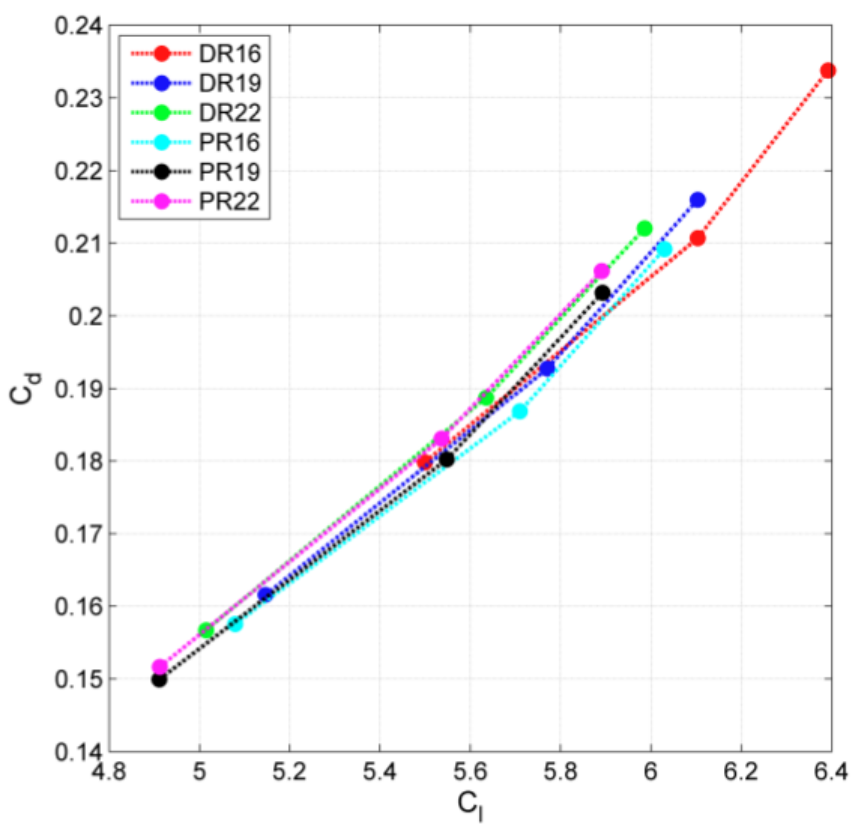

(a) Drag Polar

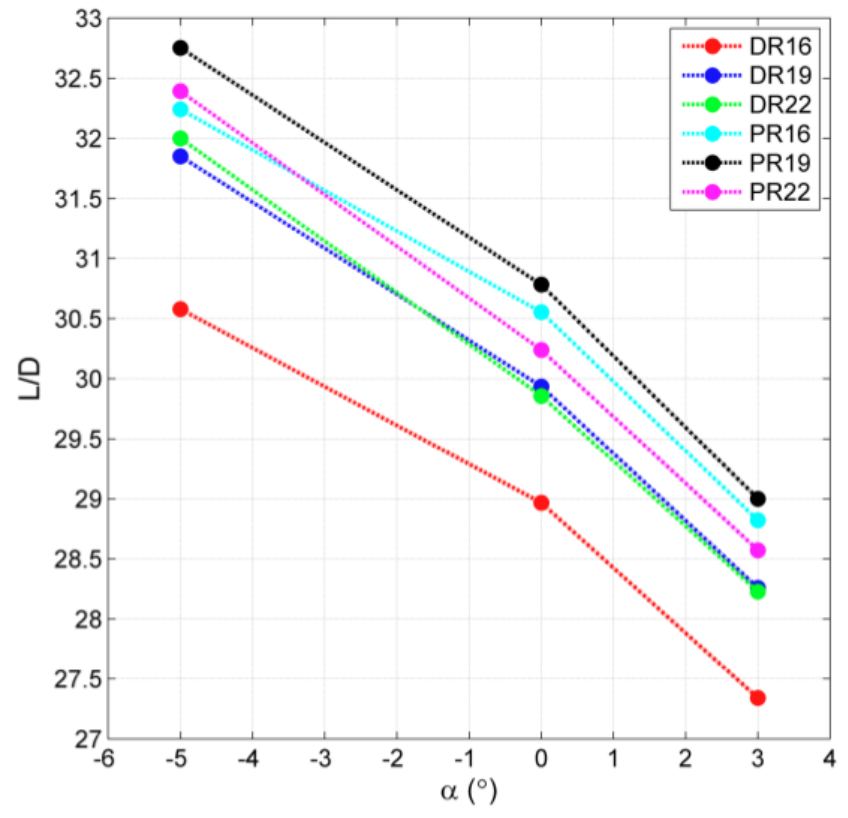

(b) Lift Over Drag

Figure 7. The aerodynamic performance of the various flap shapes at takeoff conditions.

Another area of investigation related to this work is the flow characteristics on the flap. Figure 8 shows the pressure coefficients and the skin friction coefficients for a number of flap shapes over the upper and lower surfaces. For the most part, there is little difference between the various cases before the flap. There are some slight differences near the front of the airfoil, especially the suction peak at in $C_{p}$, which account for the performance variations observed in figure 7 . What is more noticeable is the slot flow features.

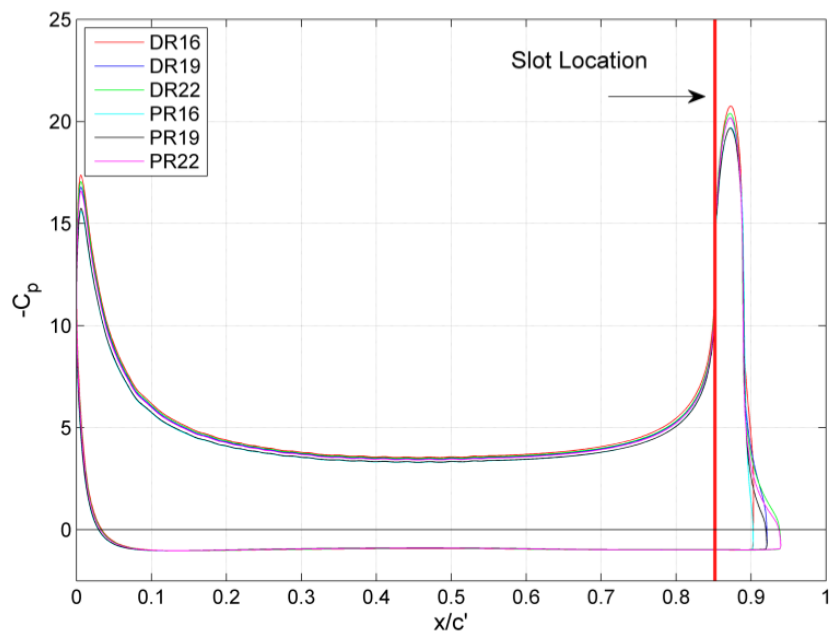

(a) Surface Pressure Coefficient

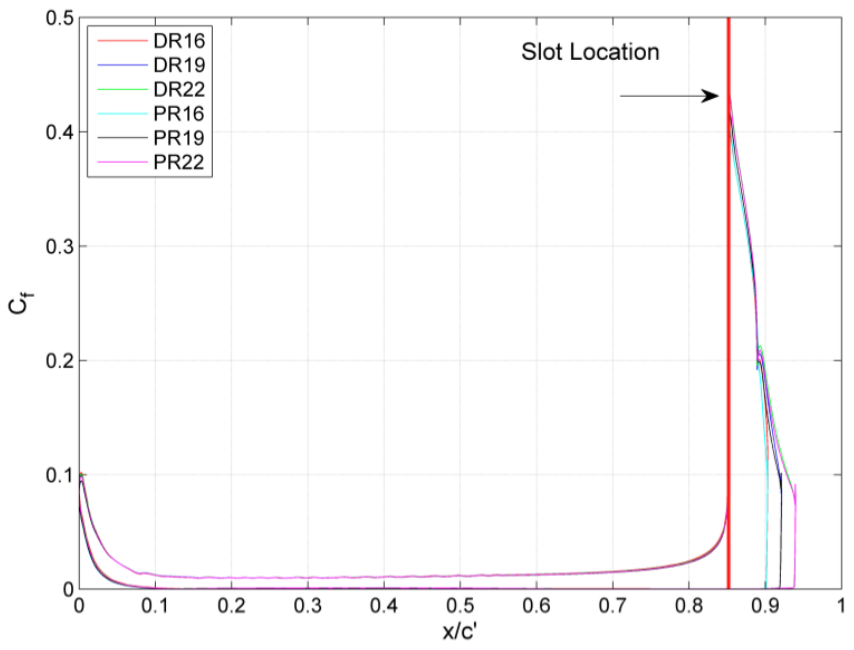

(b) Surface Skin Friction

Figure 8. The local stress (pressure and viscous) coefficients of the various flap shapes at takeoff conditions.

Figure 9 shows the pressure coefficient and skin friction coefficient for just the flap region. There is a rapid acceleration of the flow flow at the slot, which shows up as a extremely low $C_{p}$ and high $C_{f}$ at the start of the flap. Just after the flap there is a rapid increase in pressure and corresponding decrease in skin friction. This adverse pressure gradient results in a sharp dip of almost all flap shape $C_{f}$ curves at $x / c \approx 0.89$. This point corresponds to the location where the dual radius curvature changes and where the prescribed radius curvature begins to change. 
It should also be noted that the larger the prescribed radius flap the more rapid the radius of curvature change is. Comparing the three PR class flaps, the average radius of curvature for PR16 is nearly 10 times PR19 and over 100 times PR22. The one flap shape that does not exhibit this sudden drop in $C_{f}$ is the PR16 case. Future work in

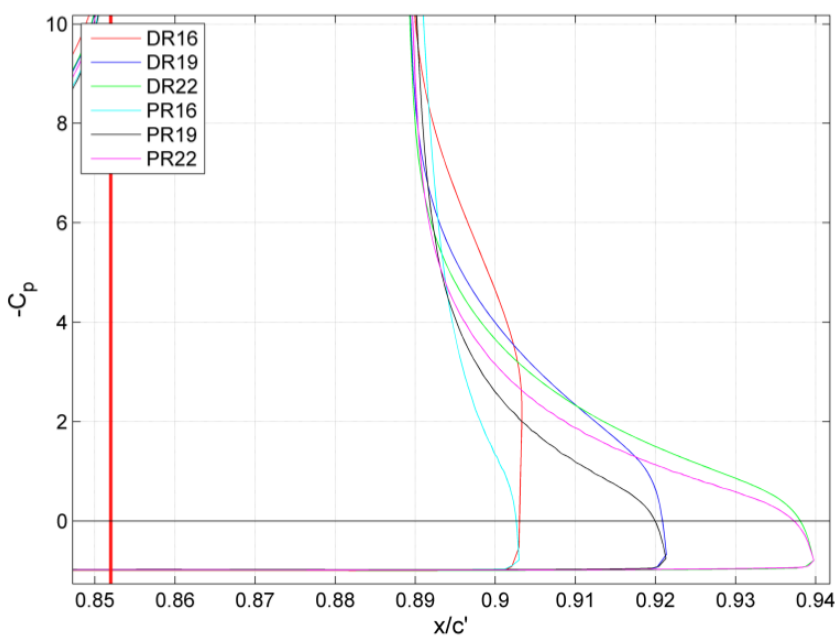

(a) Surface Pressure Coefficient

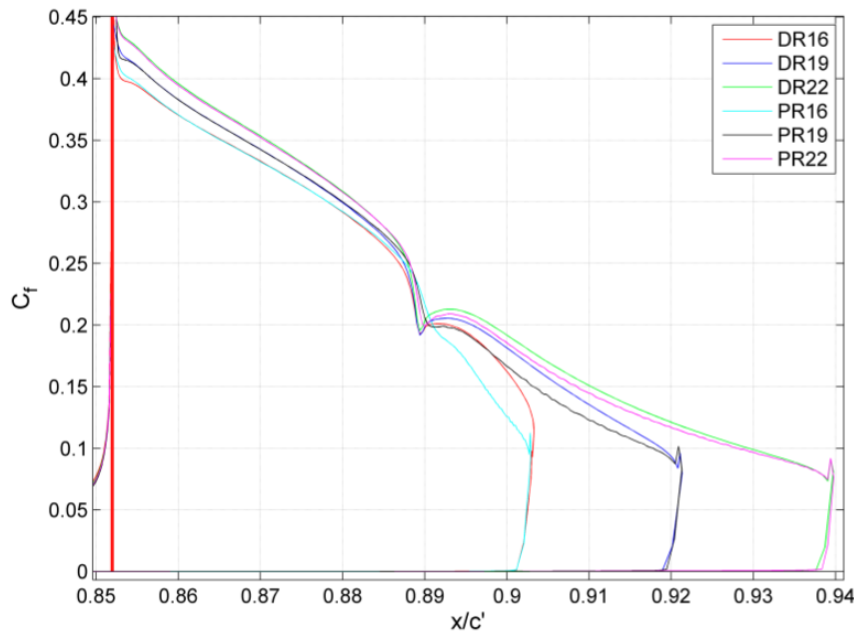

(b) Surface Skin Friction

Figure 9. The local stress (pressure and viscous) coefficients of the various flap shapes at takeoff conditions on the flaps.

this area will also include a more detailed study of this behavior. These cases were for one blowing coefficient, so it will be interesting to observe how this behavior changes with $C_{\mu}$. It could be that this same trend continues as $C_{\mu}$ decreases until the point where $C_{f}$ reaches zero, and the slot flow separates from the surface. This could be the mechanism that demarcates the start of the super-circulation region.

\section{Circulation Control Airfoil Optimization}

The Class/Shape Transformation, CST, work by Kulfan ${ }^{60}$ has been used in a variety of situations in the research at Cal Poly. In order for it to be used with circulation control technologies, the original CST method had to be enhanced to account for the slots associated with the CC technologies. Figure 10 shows a comparison between the original CST method and the multi-surface method developed by Lane and Marshall. ${ }^{61}$ CST is a curve fitting technique where a curve is constructed that minimizes the 2-norm of the minimum distances between the curve and the data points to be fit. Thus there is no guarantee that the resulting CST curve will pass through any of the data points in the set of points used to construct it. This feature is very handy when the set of points has undesirable perturbations in it that would cause a non-smooth curve to pass through the points. The problem with this feature in the CCA usage is that the slot needs to be accurately captured, as in figure 10. In order to address this, a piecewise CST method was developed, known as multi-surface CST, the performed edge detection on the input points and would automatically split the surface at edges. This is what is shown in figure 10.

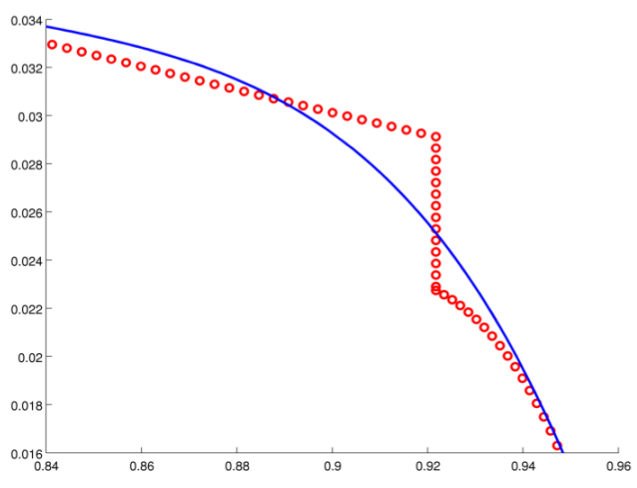

(a) Original CST Slot Treatment

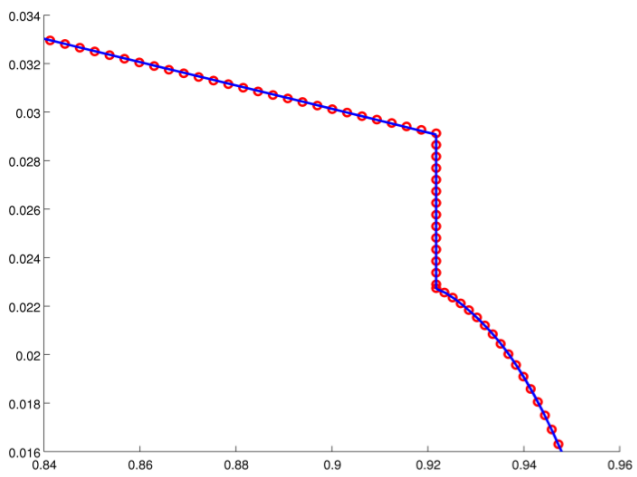

(b) Enhanced CST Slot Treatment

Figure 10. This compares the original CST treatment of the slot associated with CCA. Notice that CST's smoothing characteristic completely removes the slot while the enhanced treatment captures it. 
Lane and Marshall are developing an inverse design technique that uses the differences between the target pressure distribution and the current pressure distribution to morph the airfoil surface. ${ }^{62} \mathrm{CST}$ is used in this process to smooth the resulting airfoil shape after the morphing process. This has been tested for subsonic and transonic cases with encouraging results to date. Reference 62 provides the details of this work.

Figure 11 shows the initial airfoil shape, the target airfoil shape and the final airfoil shape. With the pressure distributions for all cases obtained by running FLUENT version 6.3.26. This was a transonic freestream flow. The iteration process required the geometry to be remeshed and a new CFD solution to be obtained. This was all performed automatically with results being obtained within a few hours. Notice that the final shape is within $0.02 \%$ of the target shape, and this took 16 iterations.

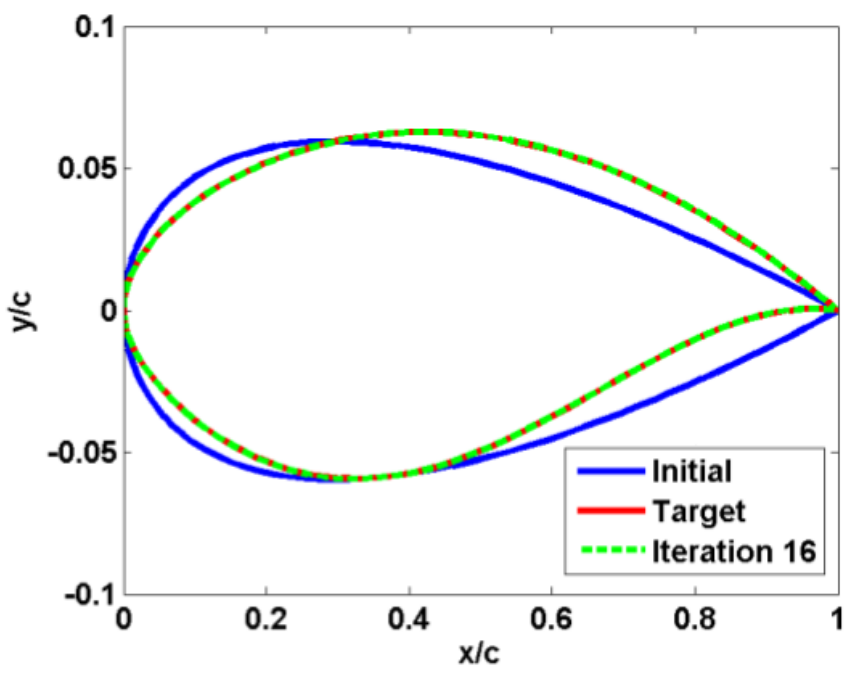

(a) Airfoil Shape

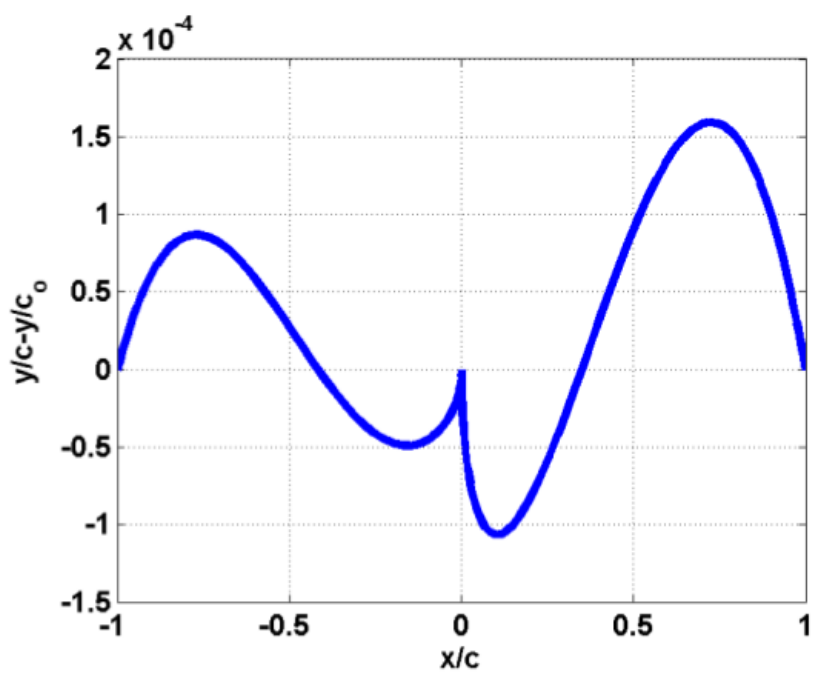

(b) Airfoil Shape Absolute Error

Figure 11. This shows the initial airfoil shape, the target airfoil shape, and the final airfoil shape after 16 iterations. This was a transonic freestream flow, and the aerodynamic data was obtained using FLUENT. Note that negative $x / c$ corresponds to the lower surface.

Figure 12 shows the corresponding pressure coefficient plots for this same inverse design case. The maximum difference in pressure is now on the order of $4 \%$. This occurs near the shock which indicates that the accurately predicting the shock location is critical to capturing the $C_{p}$ variation. In the supersonic region there appears to be non-physical oscillations in the pressure that were not able to be dampened. This work will be used to optimize CCA shapes as well as flap shapes for a given pressure distribution.

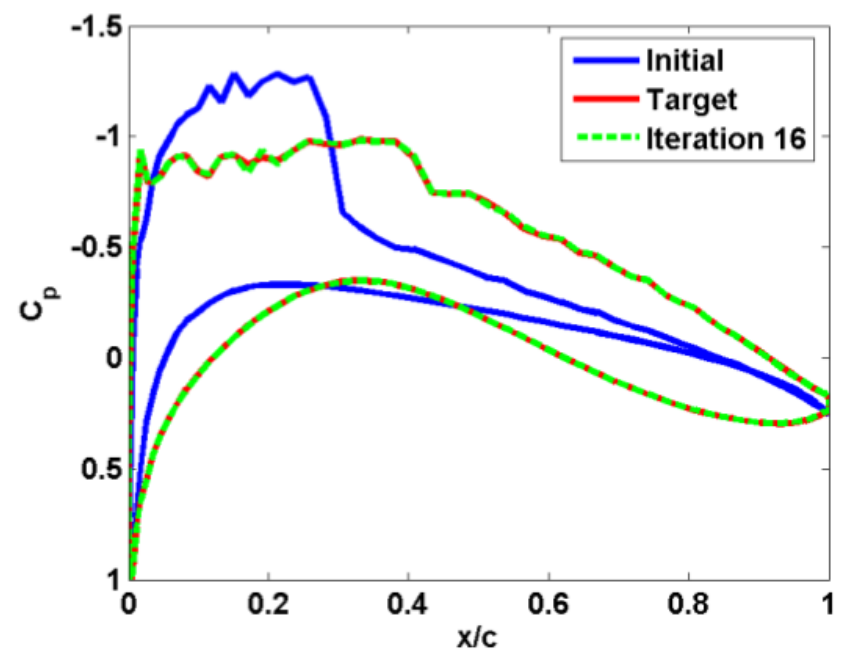

(a) Airfoil Pressure Coefficient

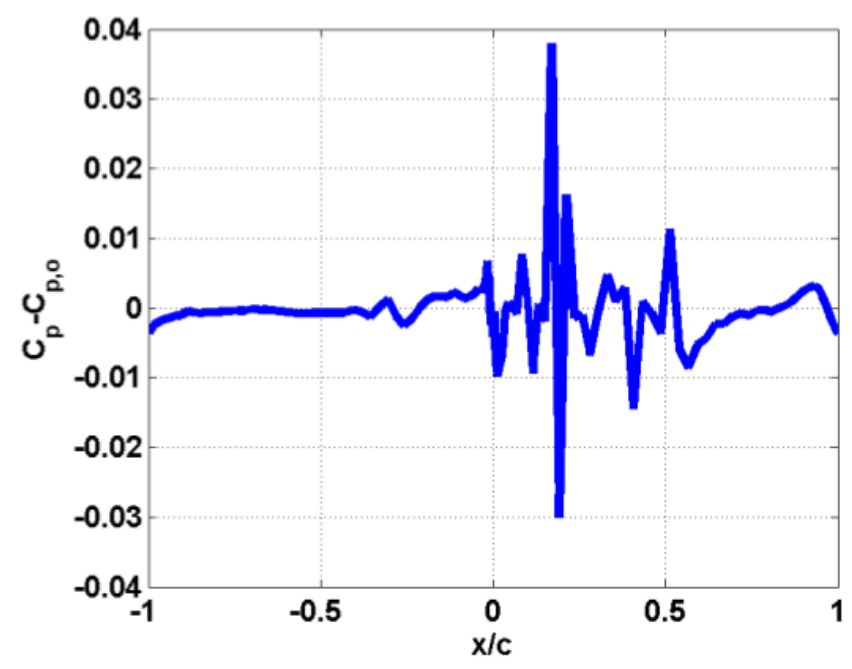

(b) Airfoil Pressure Coefficient Absolute Error

Figure 12. This shows the initial airfoil pressure coefficient variation, the target airfoil pressure coefficient, and the final airfoil pressure coefficint after 16 iterations. This was a transonic freestream flow, and the aerodynamic data was obtained using FLUENT. Note that negative $x / c$ corresponds to the lower surface. 


\section{CFD Modeling Efforts}

There are a number of CFD modeling efforts at Cal Poly that are attempting to address areas related to the specific issues of modeling circulation control technologies.

\section{Modeling Engine Exhaust and Circulation Control Flows}

Marcos and Marshall ${ }^{64}$ are modeling a simple circulation control wing which has a dual radius trailing edge blown flap and an injector engine simulator. The experimental data was from the first year effort of a collaborative NASA contract between GTRI and Cal Poly. A selection of the experimental results are shown in Englar et al. ${ }^{63}$ and Gaeta et al. ${ }^{10}$ Figure 13 shows the wing, engine simulator and relevant mounting hardware that was used in the CFD model. The wing spanned the entire width of the tunnel, so there were no tip effects, and without the engine, this would be a $2 \mathrm{D}$ experiment. A large number of cases were run by Englar, Gaeta, and co-workers, and a subset of these cases have been compared against using CFD. The computational modeling of used ICEM-CFD

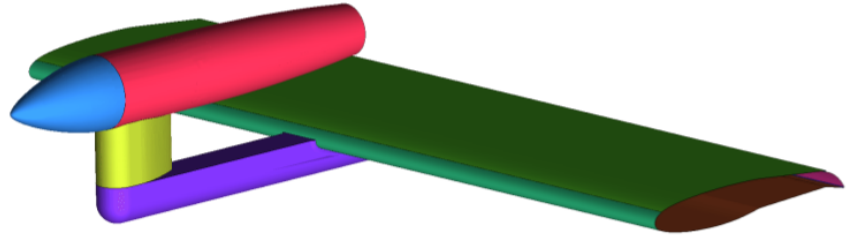

Figure 13. The geometry modeled in the CFD simulation of a circulation control wing, engine simulator, and the associated mounting hardware. This geometry is from reference 63. version 11.0.1 for the meshing, FLUENT version 6.3.26 for the CFD, and Tecplot 3602008 for the post-processing.

The mesh was an unstructured, tetrahedral mesh with layers of prismatic cells growing off the triangulated surface to capture the boundary layer regions. Most of the cells on the surface had a $y^{+}$of one or below since wall functions were not used. As is typical for these types of simulations, some of the $y^{+}$values very near the slot were slightly larger, but still within the laminar sublayer regions. A typical mesh for this work had approximately 7 million cells.

FLUENT's standard $k-\varepsilon$ turbulence model was used in its density based compressible solver. Mass flow inlet boundary conditions were used on the slot and engine regions, and the other boundary conditions were set to match the experimental data. Details of this work can be found in reference 64 .

Figure 14 shows the lift coefficient curves for two cases and the corresponding experimental data. The lower $C_{\ell}$ curve corresponds to a blowing coefficient of zero, and the upper curve corresponds to a blowing coefficient of 0.5. It is clear that the lower no blowing case is well captured while the blowing case is not. The over-prediction of $C_{\ell}$ is consistent and grows with angle of attack. This is typical of current CFD modeling of these types of flows without engine simulators and has been reported in by several researchers. ${ }^{18,19,24}$

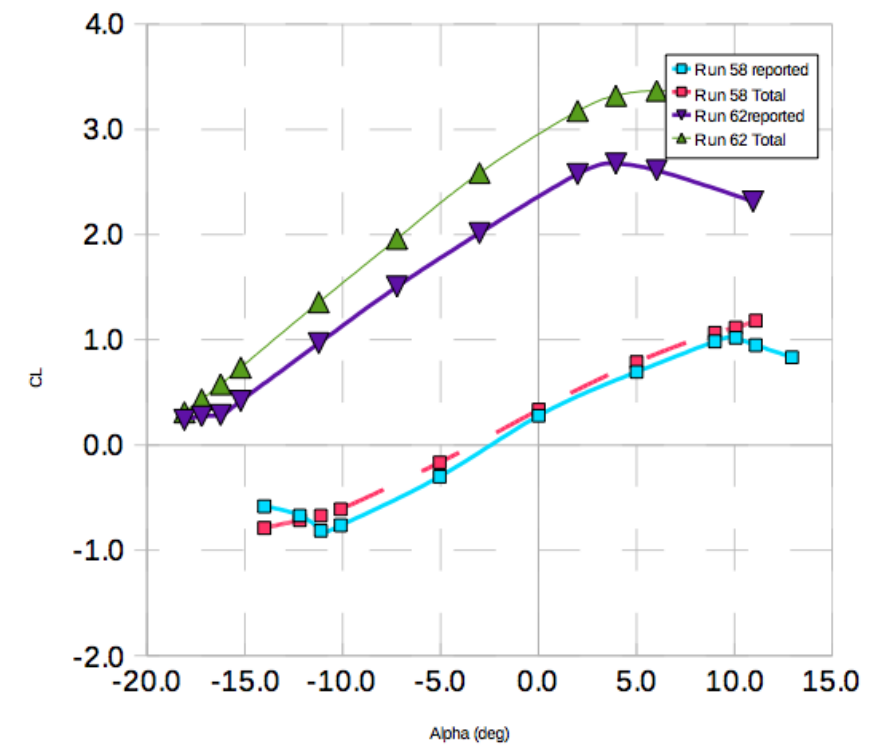

Figure 14. The lift coefficient curves for two blowing coefficient values compared to the experimental results from reference 63 . 
Figure 15 shows the lift coefficient variation with respect to blowing coefficient for two different thrust coefficient values. The experimental data for the two cases is also show. Again, the results for zero thrust coefficient show the same over-prediction of $C_{\ell}$ that have been reported previously. This over-prediction increases as $C_{\mu}$ increases. What is interesting to note is that the same trend appears for the $C_{T}=0.5$ case. This has been found to be true for a wide variety of thrust coefficients. It is believed that the use of the improved turbulence models from Section III.A will correct the over-prediction in these cases as it has in the CC airfoil analysis above. Figure 16 shows the lift

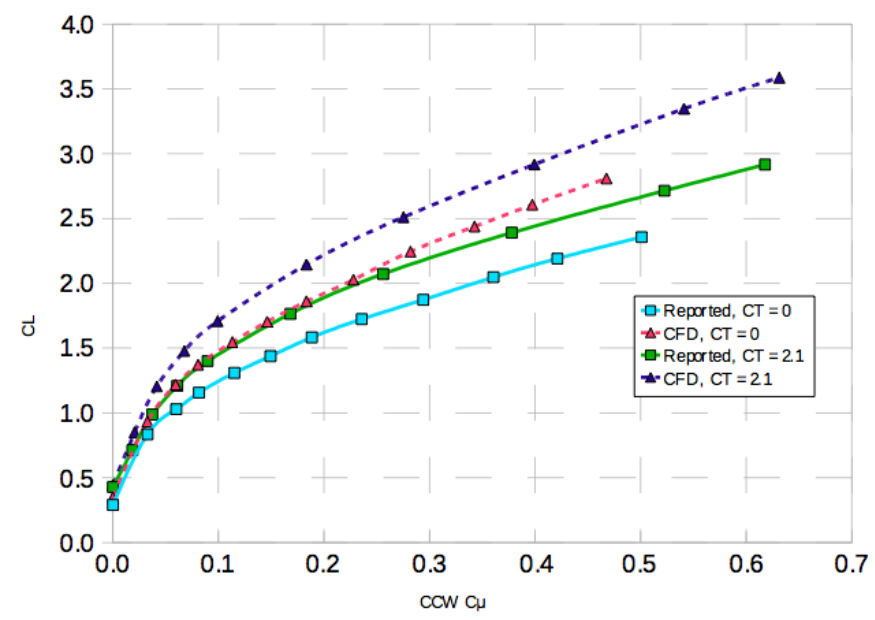

Figure 15. The lift coefficient variation with respect to blowing coefficient compared to the experimental results from reference 63 .

and drag coefficients for two separate blowing coefficients as the thrust coefficient is varied. Notice that for the no blowing case $C_{\ell}$ is well predicted through the majority of the sweep of $C_{T}$. For the blowing case, there is again an over-prediction of lift that is relatively constant throughout the sweep of $C_{T}$. There is some lift augmentation that occurs for lower $C_{T}$ values that is qualitatively captured by the CFD results.

For the drag coefficient results, these include both the aerodynamic drag and the thrust from the engine simulator since that is how the experimental data was reported. Both blowing coefficient results are very well predicted at lower $C_{T}$ values. As $C_{T}$ increases to the maximum values tested, there is some divergence between the computational and experimental results.

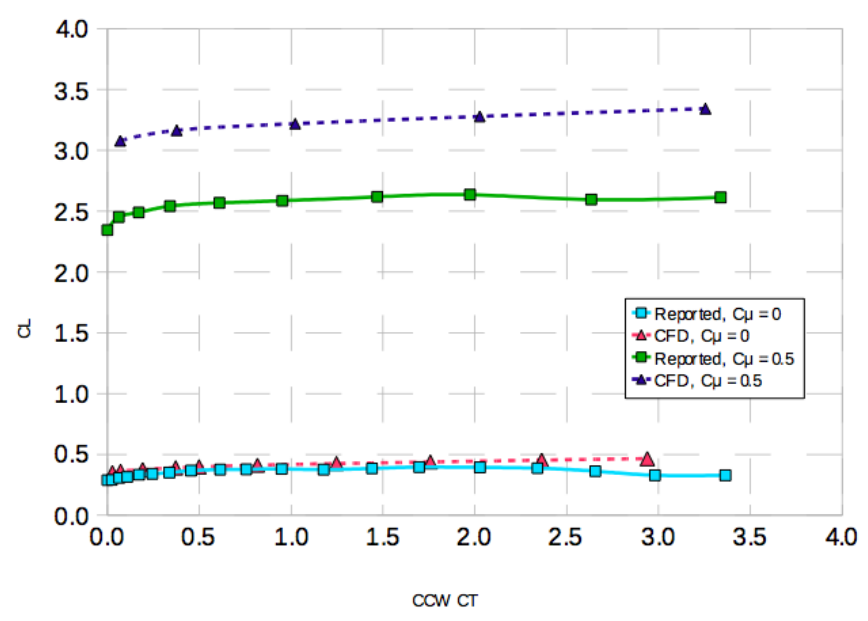

(a) Lift Coefficient Variation

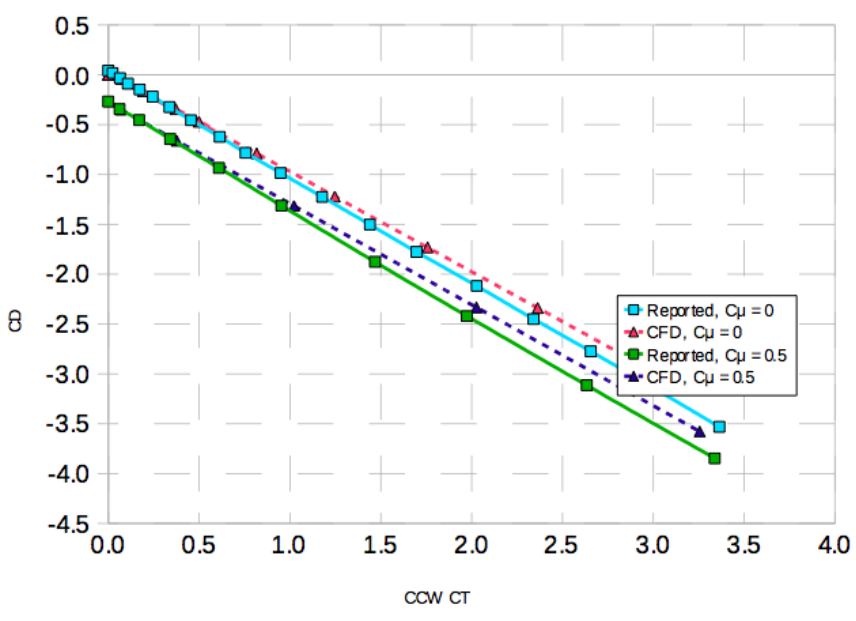

(b) Drag Coefficient Variation

Figure 16. The lift and drag coefficient variation with respect to thrust coefficient compared to the experimental results from reference 63 .

This work is ongoing. In the near future additional cases from the Englar et al. experimental data will be analyzed. Also, the $v^{2}-f$ turbulence model will be used to solve these cases and a comparison between the $k-\varepsilon$, $k-\omega$, and the three variations of the $v^{2}-f$ turbulence model will be performed. 


\section{Thrust Deflection from Slot Flow}

Currently, Cal Poly is performing a computational investigation into the deflection of the engine exhaust caused by the circulation control flow field. This work start from early numerical investigations associated with a prior aircraft design. ${ }^{65}$ This work is investigating various engine placements, by changing the height above the wing and chord location of the engine, and characterizing the amount of additional lift that is being created as the blowing coefficient and thrust coefficient are changed.

Figure 17 shows a slice through the volume mesh for one case. In order to facilitate the automation process associated with evaluating the cases, and the simplify the geometry and mesh, there is no pylon in this investigation. Once the augmented lift is better understood in this study, the effects of the pylon will be investigated. All of the mesh criteria mentioned above have been applied here. It is expected in the future the mesh will be further refined on the regions where the engine and slot flows are. Currently, figure 17 does not show any of this.

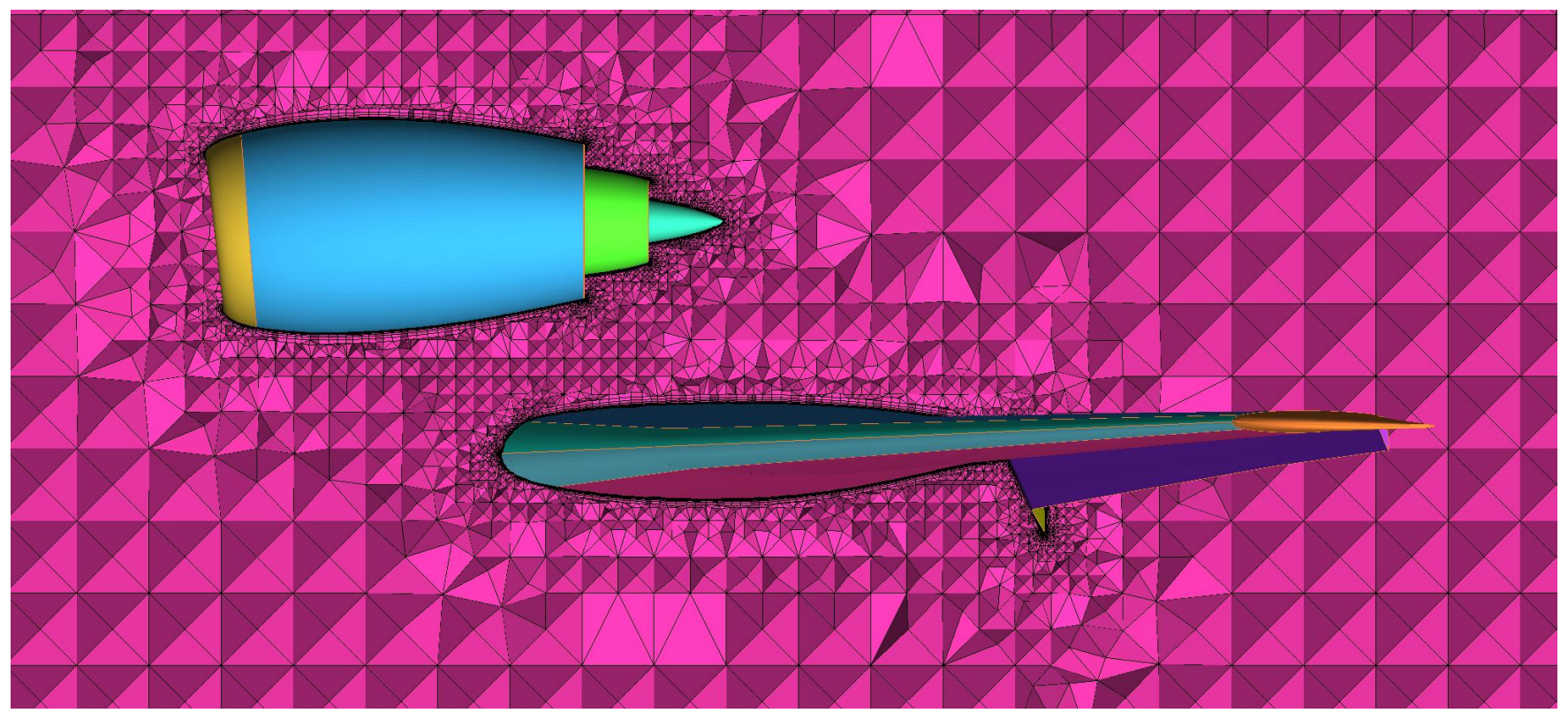

Figure 17. Slice through the volume mesh of a typical thrust deflection CFD case. Notice that there is no pylon in these simulations in order to focus on the coupling of the circulation control exhaust and the engine exhaust.

Figure 18 shows streamlines leaving the engine exit and how much deflection results far down stream. This case has a large $C_{T}$, so the noticable deflection occurs relatively far downstream compared to the lower $C_{T}$ cases. Figure 19 shows the local streamlines for the same case as figure 18. In this figure the high lift from the wings can be observed from the extreme bending of the leading and trailing edge streamlines. There is a relatively large region between the engine exhaust and the slot jet where little flow occurs. This is appears to be a relatively low pressure region with low velocity. Further investigation into how this region affects the engine flow deflection, and ultimately the amount of lift being generated. 


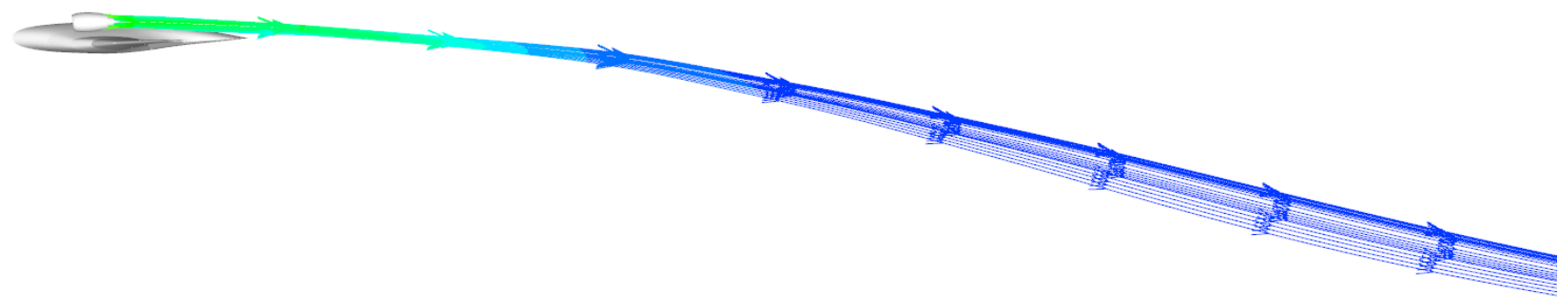

Figure 18. View of the far field which demonstrates the turning of the engine exhaust. This turning means that there is some additional lift benefits from the coupling of the circulation control slots and the engine exhaust.

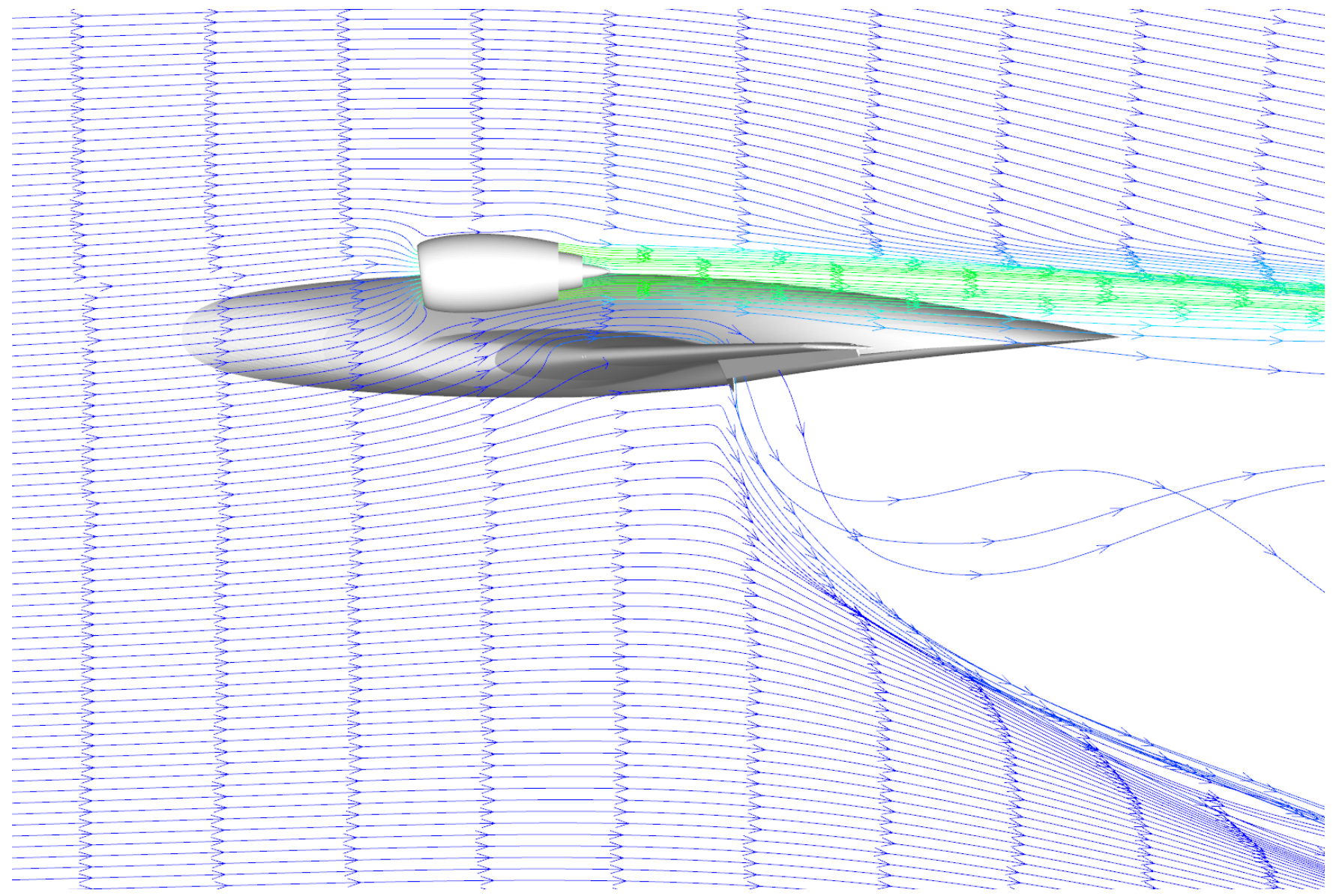

Figure 19. View of the near field which shows how much the circulation control slots deflect the local flow field. The engine exhaust is not as drastically deflected in the region near the wing. 


\section{Preliminary AMELIA CFD Modeling}

With the design of the AMELIA model recently established, Cal Poly has begun preparing the geometry for analysis. Figure 20 shows the solid model that is being used for the grid generation. One difference between the solid model shown here and the final model is the engine exit region which was recently updated to represent the dual flow TPS exhaust and related geometry. The aft end of the engine is the same as shown in figure 17.

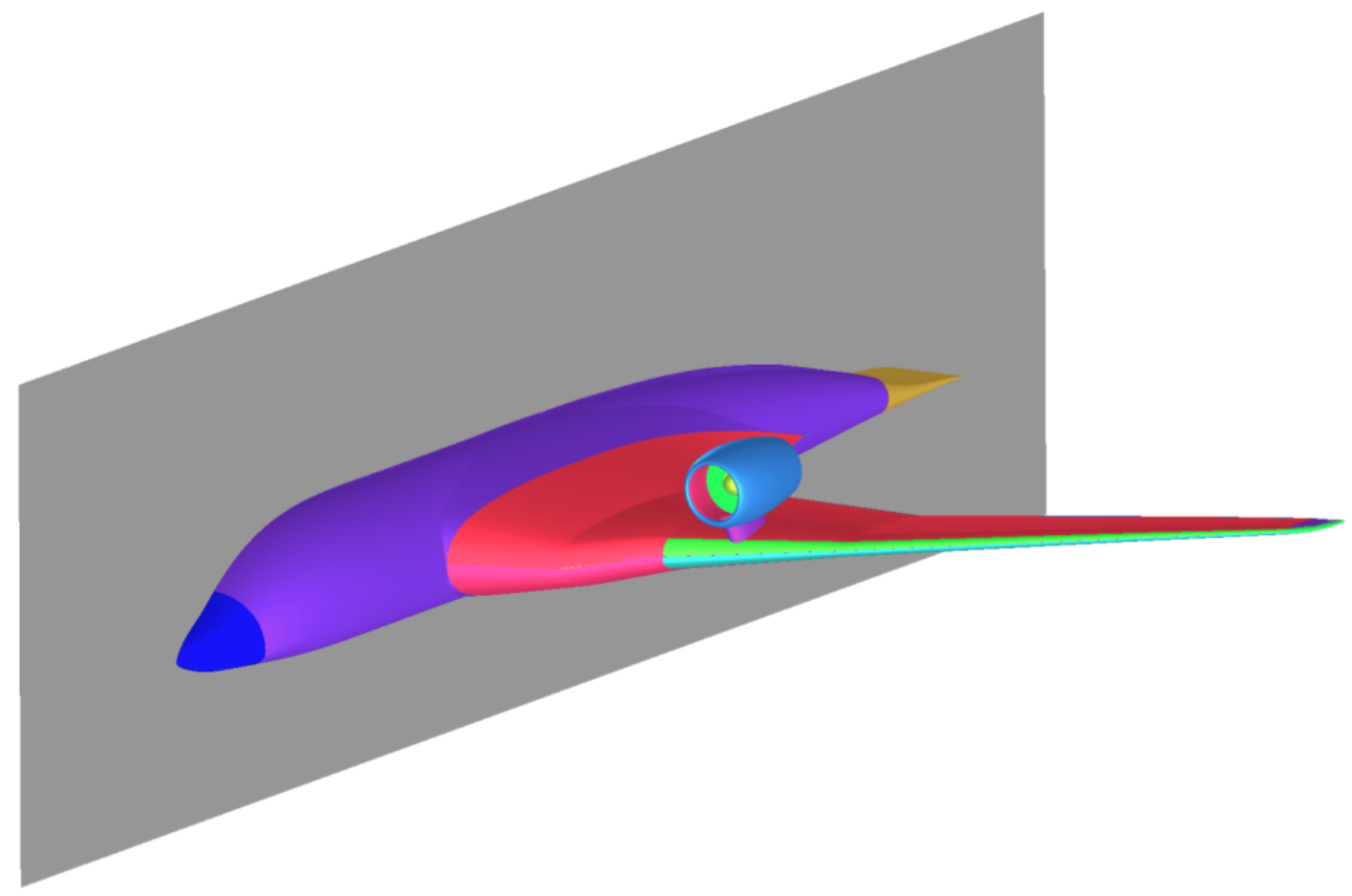

Figure 20. The geometry model (without the empennage) that is being used to develop preliminary CFD results.

Figure 21 shows some critical surface regions in the meshing process. Both the leading and trailing edges have slots, and an minimum of 5 cells across the slot is the target. This might change since some preliminary results in other work that is being performed that the plenum needs to be meshed and not use the slot face as a boundary condition. The slots also cause over-refinement of the mesh near them on the upper and lower portions of the wing, so care must be taken to coarsen the mesh away from the slots. Additional refinements to the mesh occurred near highly curved regions such as the leading edge and lip of the nacelle in order to accurately capture the geometry. Other regions that received focus were the flow field near the trailing edge slots and flaps. Since it is expected to be large flow gradients there, additional cells have been placed in those regions.

\section{Wind Tunnel Experiments to Facilitate Modeling}

\section{A. Oil Flow Interferometry}

The Fringe-Image Skin Friction (FISF) Technique, also known as oil interferometry, was chosen for the large scale wind tunnel test to measure skin friction because both magnitude and direction can be determined from a single image. The FISF technique has the advantage of maturity and reliability which becomes significant due to the difficulties of obtaining measurements in the NFAC due to its sheer size and the amount of time between tunnel shut down and the point where photographs of the model can be obtained.

\section{FISF Technique}

The FISF technique was developed by Monson et al. ${ }^{66}$ The theory behind the technique is that a single relationship can relate the thickness of the oil drop at a single location to the skin friction magnitude and direction. The oil thickness is measured via photographic interferometry. Data reduction is completed with CXWIN4GG, a PC application developed by Zilliac. ${ }^{67}$ 


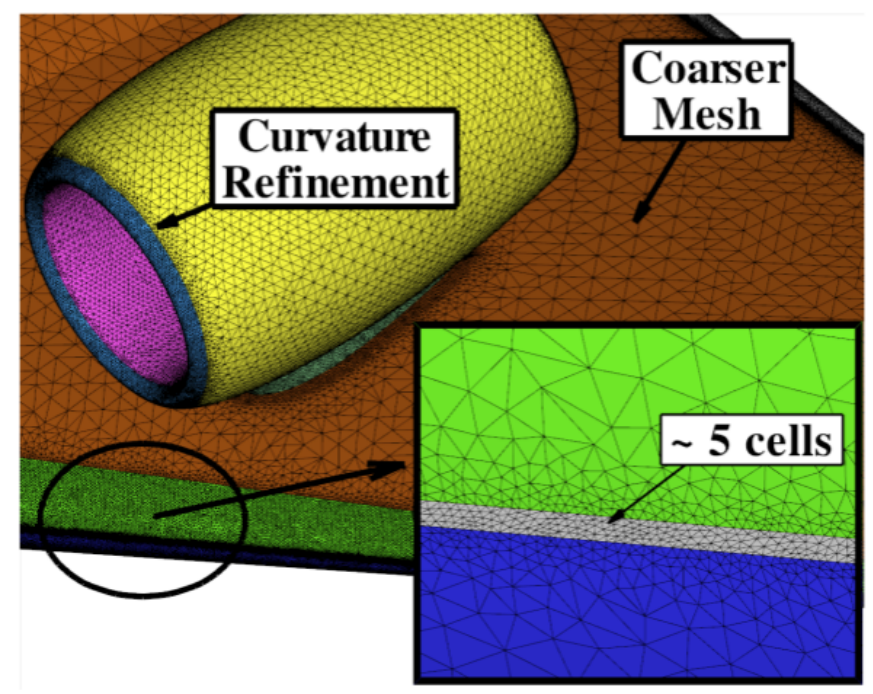

(a) Leading Edge Mesh

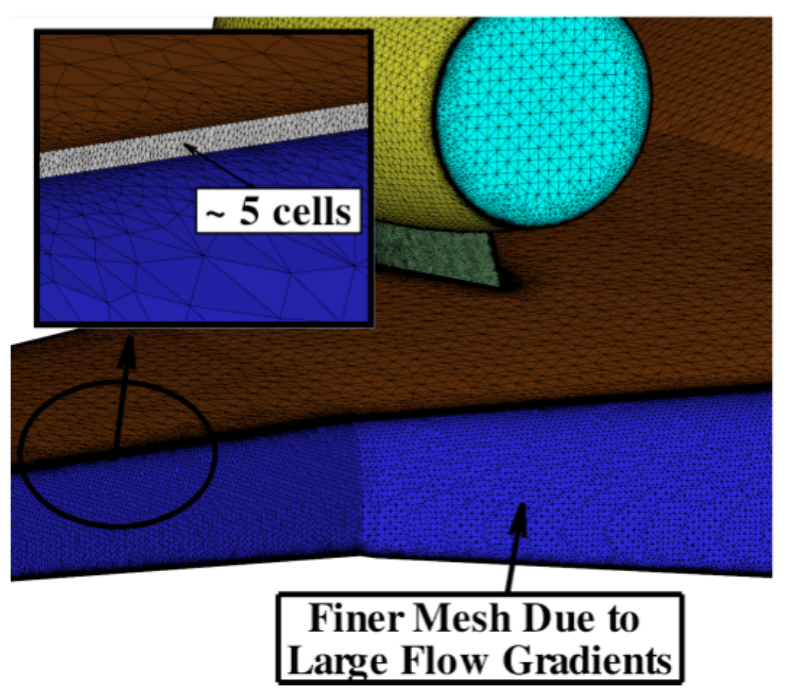

(b) Trailing Edge Mesh

Figure 21. The surface for the CFD model of AMELIA focused on some of the more complicated regions for the meshing scheme.

The FISF technique has a few key steps in its process to obtain the crucial photographs necessary to determine surface skin friction. The process is as follows: A drop of silicone oil of known viscosity is placed on the model surface. Once the oil is applied to the surface, the air flow begins, causing the oil to spread and thin. The air continues to flow for a given time, continually thinning the oil. When sufficient time has elapsed (2-20 minutes, depending on oil viscosity), the air flow is turned off. A quasi-monochromatic light source is then indirectly applied to the surface by use of a large diffuse reflector. Light is reflected from the surface of the model and oil. Two specific light rays are reflected and separated by the thickness of the oil, shown in Figure 22. Once the oil has thinned, the oil height linearly varies where con-

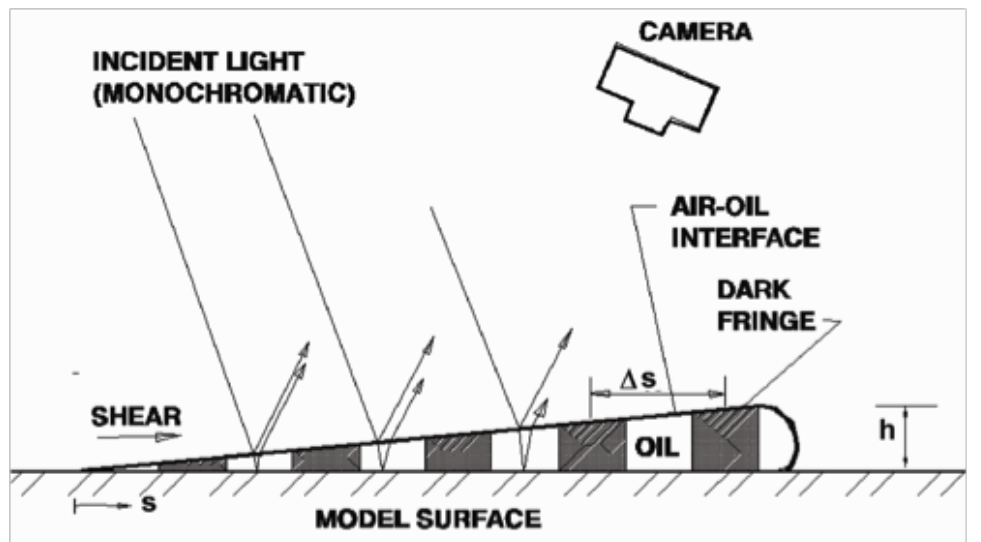

Figure 22. A schematic of the basic FISF setup highlighting the oil flow and fringe pattern on a droplet of oil from Reference 68. structive and destructive interference occurs, causing light and dark fringes on the oil surface. Skin friction is proportional to the spacing distance, $\Delta s$, on the fringes which is directly related to the thickness of the oil. The relationship for skin friction is as follows:

$$
C_{f}=\frac{\tau_{w}}{q_{\infty}}=\frac{2 n_{o} \mu_{o} \Delta s}{q_{\infty} \lambda t} \cos \left(\theta_{r}\right)
$$

where $C_{f}$ is the skin friction coefficient, $\tau_{w}$ is the wall shear stress, $q_{\infty}$ is the freestream dynamic pressure, $n_{o}$ is the oil index of refraction, $\mu_{o}$ is the oil viscosity, $\lambda$ is the wavelength of the light source, $t$ is the duration of time the oil flow was exposed to air flow, and $\theta_{r}$ is the light refraction angle through the air-oil interface. Equation (4) holds for zero pressure gradient and shear stress gradients. Further details on the oil flow technique and theory behind it is covered by Naughton and Sheplak. ${ }^{68}$

\section{Application of FISF to AMELIA}

In order to successfully apply the FISF technique, the fringes on a model need to be clearly visible. Fringe visibility is based upon the surface finish of the model. An ideal surface is extremely smooth with consistent and durable optical properties. Based on a study by Zilliac ${ }^{69}$ the best fringes appeared on high flint content SF11 glass manufactured by Schott Glass of Germany, which is an impractical material for a wind tunnel model. A practical surface finish for 
a model would be mirror like, which can be achieved with nickel plating the model surface. Acceptable substitutes have been made utilizing polished stainless steel or black Mylar sheets applied to the model surface. Black Mylar sheets offer the most cost effective solution for oil flow testing. However, at higher speeds and long run times Mylar would begin to peal along the edges, ruining any data downstream. The continual Mylar reapplication to the model would prove time consuming and impractical due the model height in the NFAC for the AMELIA test. Mylar is also difficult to apply to a 3D surface, usually resulting in small wrinkles in the Mylar distorting the skin friction measurements. Polished stainless steel and nickel plating have the durability that Mylar lacks. Nickel plated aluminum is less expensive than polished stainless steel. For these reasons, a nickel plated aluminum model was chosen for the large scale wind tunnel test.

In order to properly view the fringes, a monochromatic light source must be reflected off a diffuse reflector. In large wind tunnel applications, the tunnel walls have been used as the reflector. ${ }^{70}$ Unfortunately, the NFAC tunnels walls are composed of a matte metal mesh covering a deep, perforated acoustic liner, rendering the walls unable to sufficiently light the tunnel. The next option is to build a reflector which encompasses the portion of interest on the model. A small hole would be cut in the reflector allowing a camera to capture the fringe spacings; a setup such as this is shown in Figure 23. AMELIA has a highly curved blended wing which causes additional difficulty in the image processing. Due to the models highly polished and curved surfaces, the camera will see reflections from a large area of the wind tunnel. Therefore, if the wind tunnel is being used as the diffuse reflector, large areas of the tunnel need to be white. Since this would be costly in the NFAC, it is necessary to use a curved diffuse reflector. It will ensure the model is uniformly lit allowing for accurate fringe spacing identification and does so with fewer lights. The type of diffuse reflector used on the wing blend is also shown in Figure 23.

The angle at which the light enters the camera

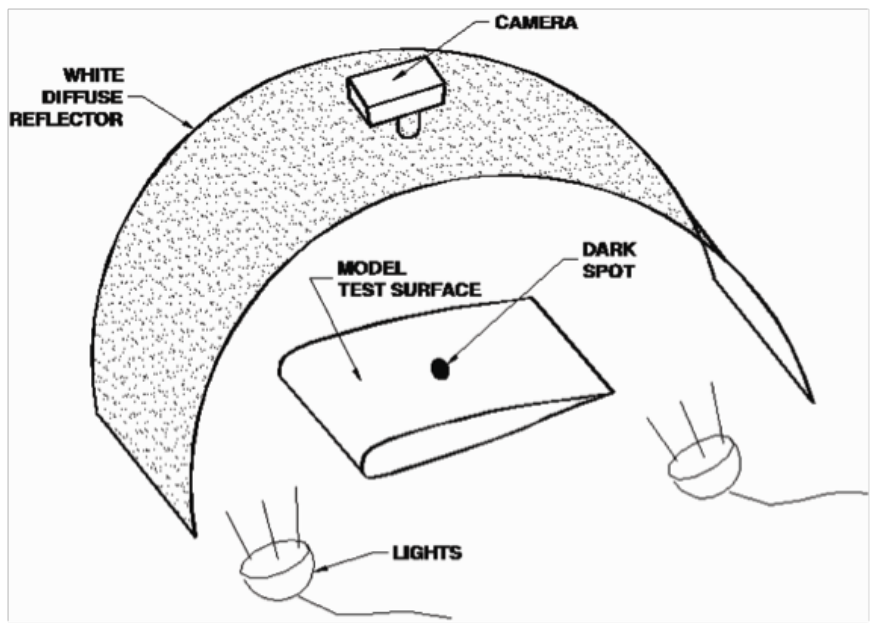

Figure 23. The FISF solution used for the wing blend. The dark spot is due to no light being reflected by the camera lens. can greatly affect the skin friction measurement, especially at large angles such as leading edges or the blended wing portion of the model. Zilliacs CXWIN4GG software utilizes single camera photogrammetry to determine the angle of the light reflecting off the oil on the surface of the wind tunnel model. This is made possible by using fiducial marks over the model surface. The camera captures an image encompassing the entire wing with several fringes over the wing surface. Within that image are multiple fiducial marks with known locations on the model coordinate system. Zilliacs software completes the photogrammetry by matching the known fiducial marks locations (both a pixel $x-y$ coordinate system as well as the model coordinate) to a given set of model points. This allows the software to calculate the light incident angle at any visible point on the model.

Due of the size of the NFAC, a special procedure has been devised to ensure accurate fringe production. Normally the tunnel transients are short, resulting in little error from the startup and shutdowns. However, the NFAC requires a minimum of 5 minutes to startup and shutdown which can introduce unacceptable error into the skin friction measurements if the incorrect viscosity of oil is chosen for the test. In order to ensure recording accurate fringes, the model will be at a high angle of attack during the tunnel startup allowing separated flow (low to no shear) over the wing. Once the tunnel freestream has been reached, the model will be positioned to the angle of attack of interest. At this point, slot blowing and the turbine simulators will be started as well. The model will remain at this test condition for a minimum of 20 minutes. Once the oil is sufficiently spread, the slot blowing, turbine simulator, and tunnel freestream will be turned off, while the model is once again pitched upward to cause separation over the wing allowing the fringes to be unaffected by the shutdown procedure. Once the flow has stopped, the diffuse reflector and camera will be brought into the tunnel. The model will be inverted for the skin friction measurements, allowing for optical access to the suction side of the airfoil without having to be physically be placed above the model. A diffuse reflector will be held up to the model, lighting it, while a second person will capture the fringe spacings in two images. This process is time consuming, but worthwhile to ensure quality data for CFD validations to be made against. For this reason, only eight to ten key test conditions will be investigated with oil interferometry for CFD validation. 


\section{Application of FISF to Blended Wing Section}

In order to prepare for the skin friction measurements on AMELIA first skin friction magnitude and direction measurements will be completed on the three-view of wing section shown in Figure 24. The blended portion (the shaded portion of the three-view shown in Figure 24) is representative of the wing blend on AMELIA. The lighting technique and wind tunnel procedure are similar to the AMELIA test, aiding in the preparation for the AMELIA test. In addition, the test will create a database of global skin friction measurements for CFD validation on a blended wing geometry. The two foot wing section was manufactured by Patersonlabs, Inc. Ideally, a scale model of the AMELIA wing blend would have been made, but a size constraint was placed on the test article by the demotions of the wind tunnel available for the pretests at Cal Poly and by the stock available at Patersonlabs, Inc. to reduce cost of the article. The test article chord needed to be less than 6 inches, have a thickness of less than 3 inches, and must have the ability to remove the model from a 6 inch wind tunnel access hole. For this reason, a long 2D section was machined, with a small 3D section at the outboard. Note that the lower surface of the test article does not match AMELIA. To correctly blend the upper and lower surfaces, the $2 \mathrm{D}$ chord length would have to be scaled down to a point too thin to reasonably manufacture. It was most important to match the upper surface of the test article to AMELIA, so the blended airfoil was shifted up, causing the lower surface to not match AMELIA.

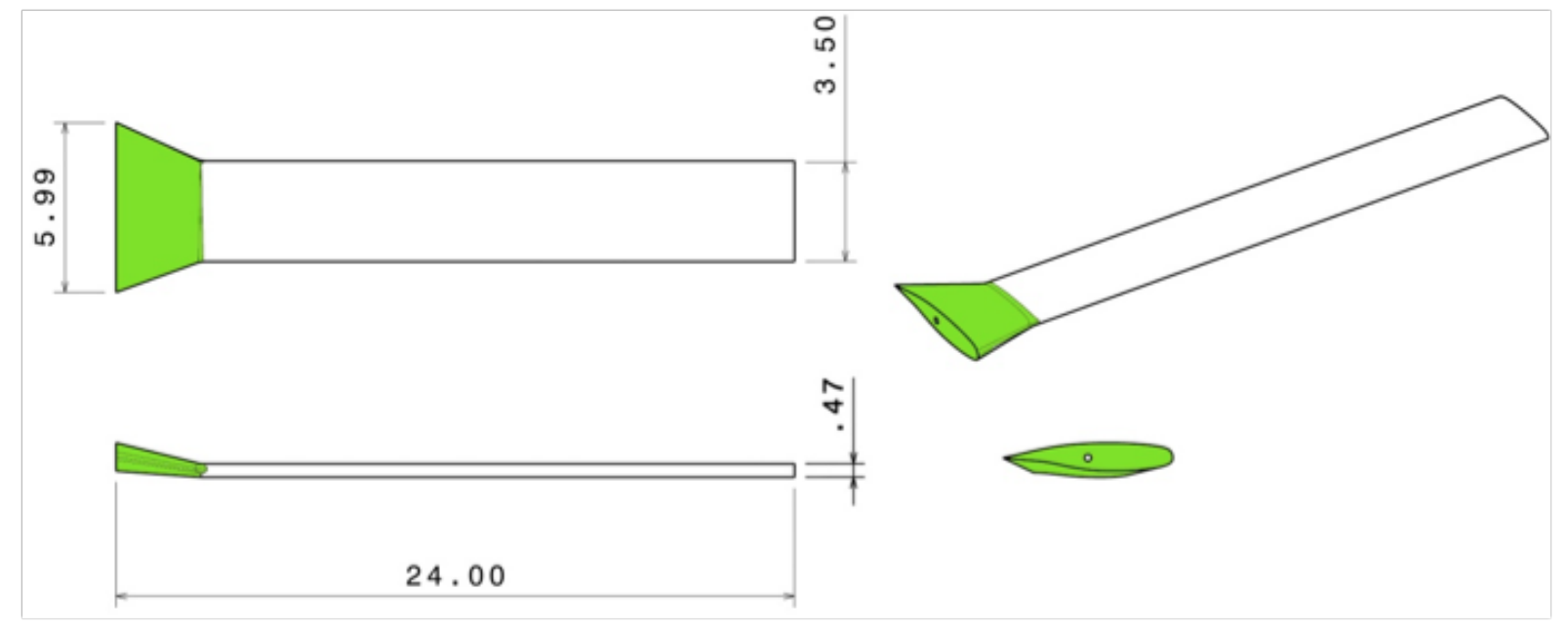

Figure 24. Three view of blended wing where the $3 \mathrm{D}$ wing blend section is shown in green and the $2 \mathrm{D}$ section is left white (all dimensions are in inches).

The test article for the pretest experiment was also nickel plated to allow as many similarities to the AMELIA test as possible. The plating has yielded excellent fringe visibility; a sample fringe is shown in Figure 25. The fringes shown were created using high pressure air and a half cylinder white diffuse reflector. The full wing will be tested in the Cal Poly Mechanical Engineering 2x2 foot low speed tunnel. Fiducials were not added to the test article during manufacturing therefore small stickers will be applied on to the model randomly. By use of a Faro Arm the fiducials locations will be determined relative to a chosen coordinate system. Multiple runs will be made to ensure repeatability in the experiment and create a more complete dataset. A similar tunnel start/shutdown procedure will be utilized on test wing section as is currently planned for AMELIA.

\section{B. AMELIA Model and NFAC Test}

\section{Overview}

The model is approximately a $1 / 13$ scale of an aircraft designed as a 100 passenger, N+2 generation, regional, cruise efficient short takeoff and landing (CESTOL) airliner with a

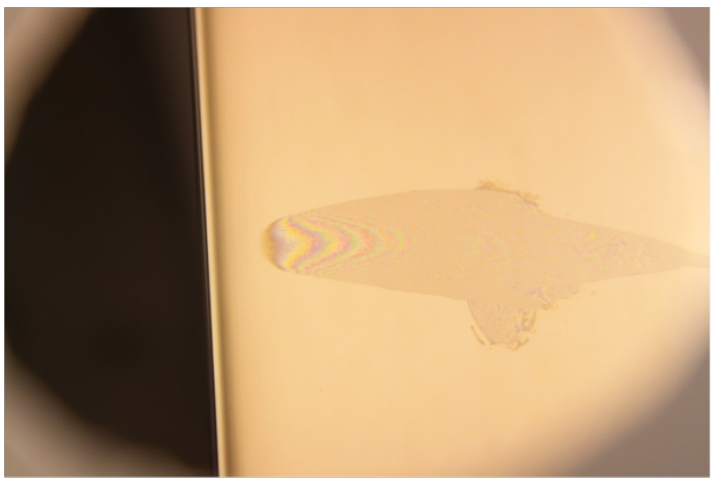

Figure 25. Fringe on test nickel plated wing, using 10cSt oil and compressed air to create fringe. Wing is lit with a diffuse reflector and mercury vapor bulbs. The color bands on the fringe appear because no dichroic filter was used. 
hybrid blended wing-body and circulation control developed by David Hall. The designed is aimed at the fuel-savings and noise goals set out by the $\mathrm{N}+2$ definition, of $25 \%$ reduction in fuel consumption and progress towards $-52 \mathrm{~dB}$. A three view drawing with a few basic dimensions of the model is shown in Figure 26.
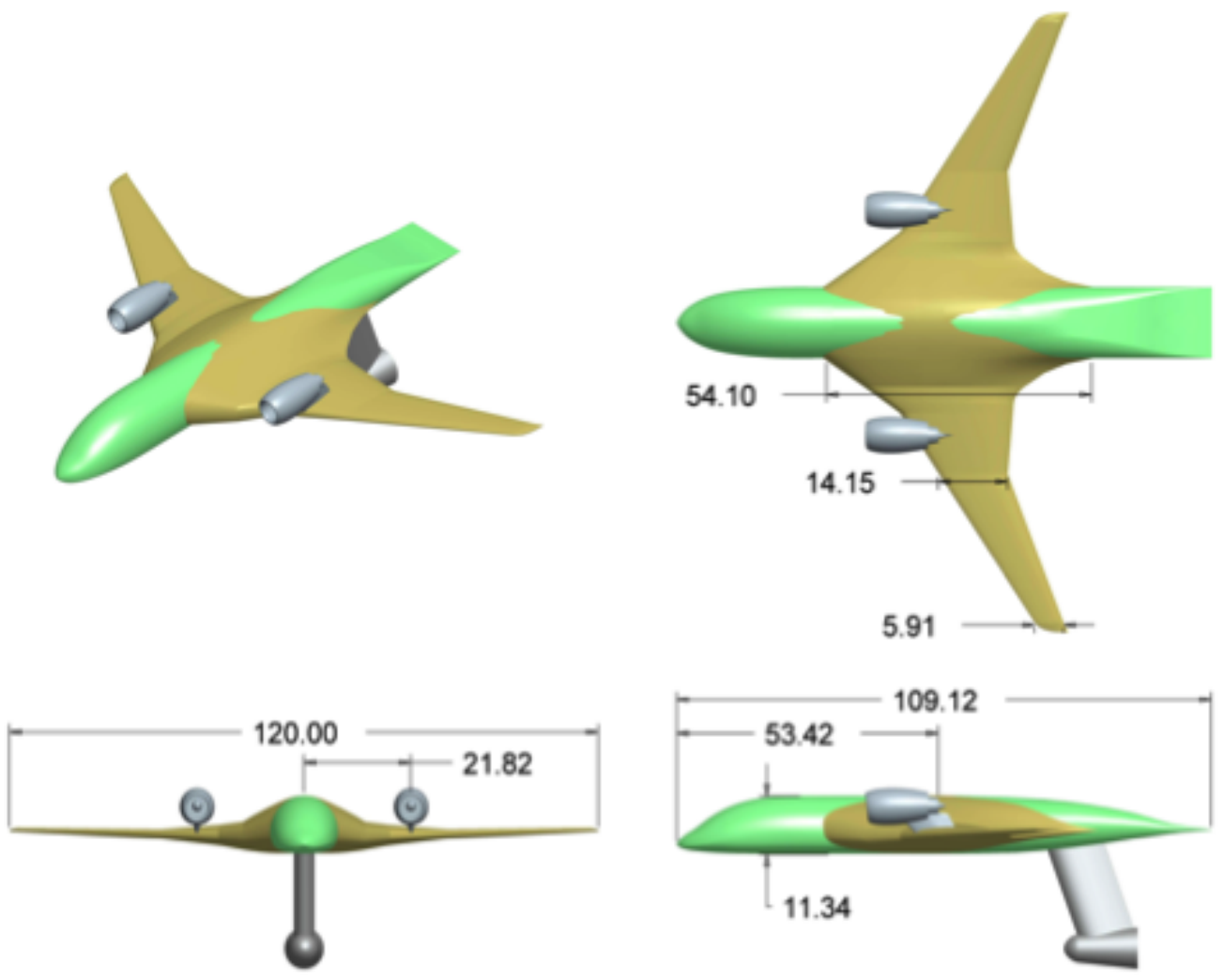

Note: All Dimensions In Inches

Figure 26. Three view schematic of the model mounted to the sting with empennage removed.

The design of the wind tunnel model was based on testing goals, manufacturability, and future capabilities. Most of the outer mold lines of the model were taken off of the design set forth by David Hall, with the exception of the engine nacelle, engine pylons, and flaps. Research, design, and development went into each component of the model, which was then integrated with the rest of the model. The model will be provided with powered-lift by $0^{\circ}, 30^{\circ}, 60^{\circ}$, and $80^{\circ}$ circulation control flaps and over-the-wing engine locations. Key components of the model include leading and trailing edge plenums, dual radius flaps, a high pressure system, a low pressure system, attachable empennage, and turbofan propulsion simulators. Most of the model instrumentation takes place on the left half of the model, which includes 230 static pressure ports, 8 unsteady pressure Kulites, and a cross-correlation rake. The model forces will be measured by an eight inch diameter, flow-through balance that is supported by blade attachment to the sting. The models internal systems and external features are shown in Figure 27.

The size of the wind tunnel model was set by the NRA and the dimensions of available wind tunnels, which scaled the model to a $10 \mathrm{ft}$ span. Since the main focus of the design was on the acoustics and aerodynamics of the N+2 design, the testing plans did not require empennage control surfaces. However, in preparation of future research, off blocks were installed and empennage control surfaces were manufactured including a V-tail, strakes, and a structural rudder. The design of the model takes into consideration future capabilities and features that can be employed for future use and research.

\section{Manufacturing of the Model}

Patersonlabs, Inc. competed and won the contact to manufacture the $10 \mathrm{ft}$ span model. It is projected that the model will be completed in early in the calendar year of 2010. Currently Patersonlabs, Inc. has cut several key elements of the model, including the right and left portions of the wing, the empennage, and the fuselage. Cal Poly is receiving regular progress reports from Patersonlabs, Inc and is in constant communication regarding manufacturing needs. Figure 28 shows photographs from the most recent progress report showing the lower front end of the fuselage 


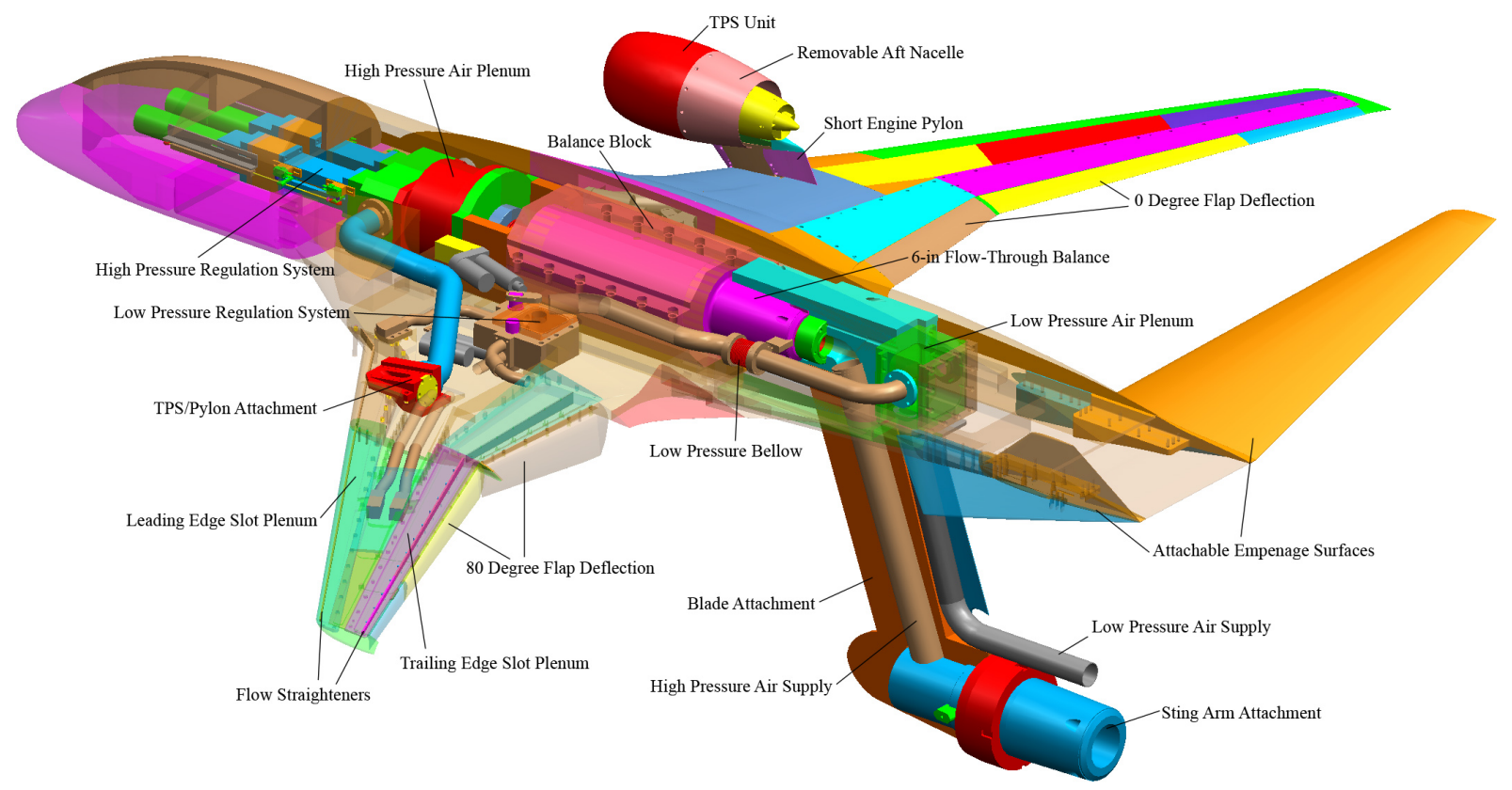

Figure 27. Cut-away view of the internal components of AMELIA.

in the CNC machine being cut and the attachable strakes after completion.

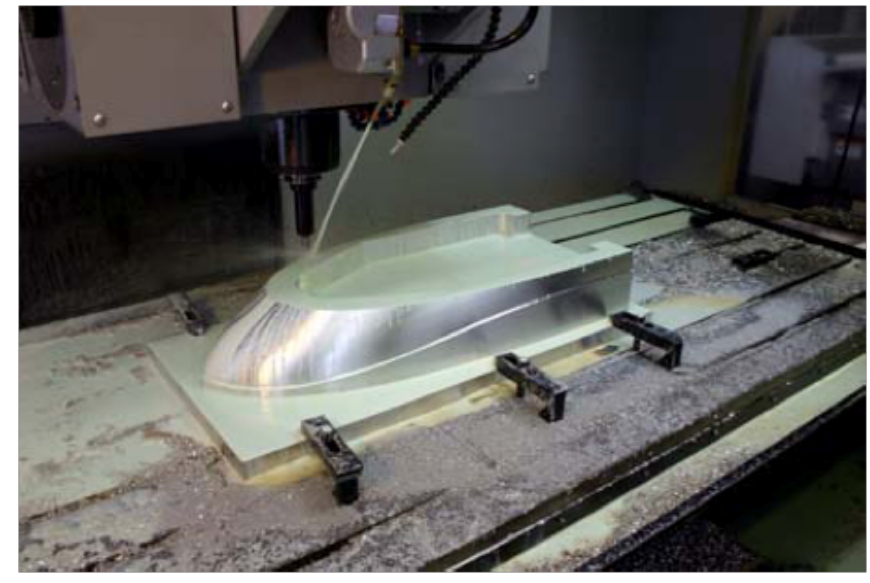

(a) Front lower section

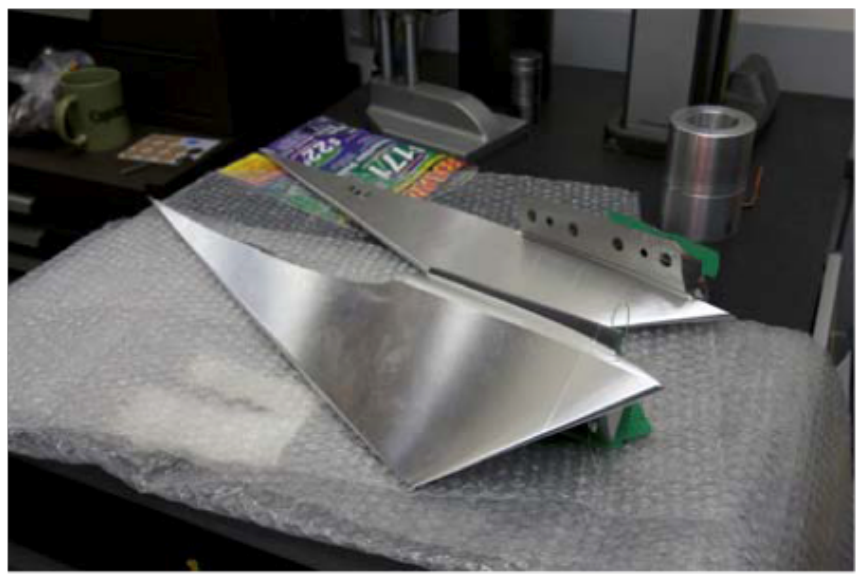

(b) Attachable strakes

Figure 28. Photographs of sample sections of AMELIA the is currently being manufactured by Patersonlabs.

\section{AMELIA in the NFAC}

After a detailed trade study was performed, it was determined the $40 \mathrm{ft}$ by $80 \mathrm{ft}$ NFAC was the most appropriate wind tunnel to test the AMELIA model. The main advantages the NFAC provided are simultaneous acoustic and aerodynamic testing along with a high pressure air system to operate the propulsion simulators for the powered lift aspect of the model. The model loads were an important characteristic in determining the appropriate support system for the AMELIA model in the NFAC. Although the model $10 \mathrm{ft}$ span will only occupy $25 \%$ of the of the tunnels width, the model loads will be significant due to the powered lift design. The model will utilize an 8 inch diameter balance (shown in pink integrated in the model in Figure 27) with the current predicted loads being well within the loading limitations of the balance and sting support system. Figure 29 shows the model mounted in the NFAC test section with the relative size of the model accurately depicted in the schematic. Acoustic measurements will be obtained by six stationary far field microphones, a $30^{\circ}$ sideline stationary microphone, and one large stationary microphone array. The far field microphones will be placed along the centerline of the left TPS unit of the model on 
the floor of the test section in the wind tunnel. Five of these microphones will be placed ten degrees apart, traveling aft, below the model, with the first microphone located directly below the TPS of the model. The sixth microphone will be placed 20 degrees in front of the microphone directly underneath the model. The stationary microphone layout is displayed yellow in Figure 29. Along with the six stationary microphones, there will be one microphone that will be placed on a rail running the length of the wind tunnel that will be offset to the left 30 degrees from below the model. All of these microphones will be mounted to the tunnel using five foot tall, airfoil struts that will be $38 \%$ thick. A stationary array of 70 microphones placed in a spiral pattern will be placed directly underneath the models right TPS unit allowing for isolated noise signatures from the powered lift design of the model. Figure 30 shows the current tunnel microphone arrangement.

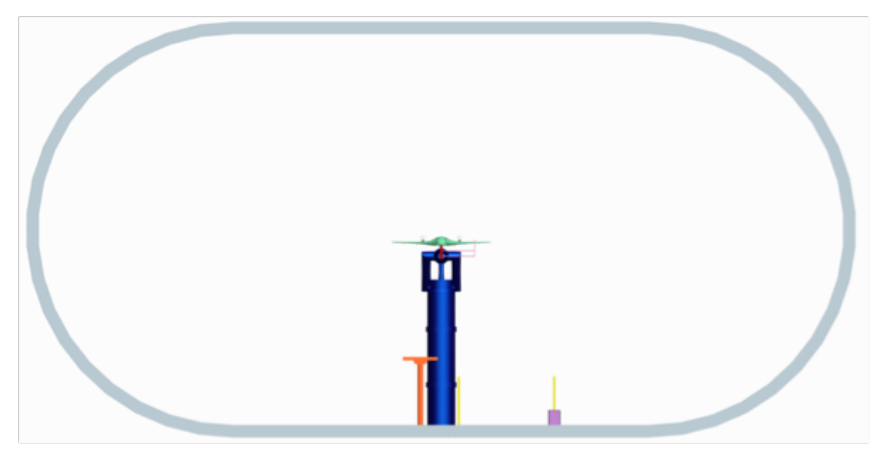

(a) Front view

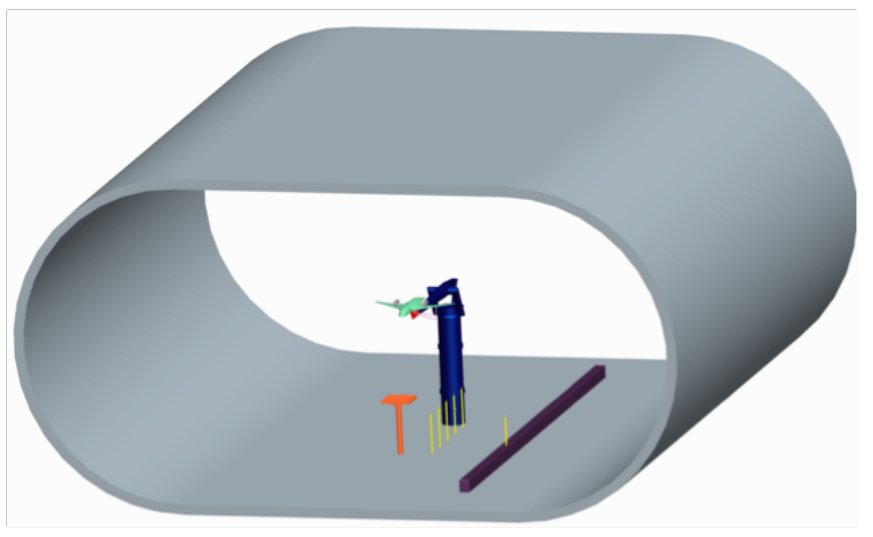

(b) Isometric View

Figure 29. Front and Side view schamatics of AMELIA mounted in the $40 \mathrm{ft}$ by $80 \mathrm{ft}$ NFAC test section.

\section{Test Plan}

Currently, the AMELIA model is slated to be tested in May of 2011. The model is projected to be in the NFAC for approximated 10 weeks with seven weeks dedicated to wind-on time. The existing test plan allows one to two weeks for model checkout, model tares, and basic Reynolds number sweeps. The next two to three weeks are dedicated to obtaining detailed data for eight to 10 test points. Several different model configurations will be considered: the variables for the model are engine simulator height, thrust coefficient, blowing coefficient, empennage configuration, flap configuration, pitch and yaw. The measurements obtained during this period will be forces, moments, surface pressure distributions, unsteady pressure measurements, skin friction, boundary layer thickness, far field acoustic noise, and acoustic array measurements. The model will be oriented inverted to allow for ease and obtaining the skin friction measurements. Once the eight to 10 test points are completed the model will and then reoriented right-side-up and the eight to 10 test points will be repeated. The remainder of the wind-on tunnel time will be dedicated to obtaining several operating conditions with a smaller subset of measurements. Several pitch sweeps will be conducted $\left(-5^{\circ}\right.$ to $\left.+20^{\circ}\right)$ and yaw sweeps $\left(-20^{\circ}\right.$ to $\left.+20^{\circ}\right)$ will be performed with the goal of obtaining data for CFD validation.

\section{Conclusion}

Cal Poly researchers have improved several areas of Circulation Control Modeling through the past few years and are planning on more improvements in the years to come. Improved turbulence modeling has so far yielded a lot of 
promise in handling a wide range of $\mathrm{CC}$ flows that the past literature has shown to be difficult to model. Meshing techniques have been developed to improve the CFD solution quality of complicated configurations that utilize CC technologies. Techniques have been developed to improve the utilization of CC technologies in an aircraft design context, such as takeoff and landing models and propulsion system and aerodynamics integration. Finally, further advances are planned with the large scale wind tunnel test activities planned for the NFAC in the summer of 2011. These results will provide Circulation Control validation data for future modeling efforts.

\section{Acknowledgements}

Some of this work was sponsored by the Department of the Navy, Office of Naval Research, under award \#N0001406-1-1111. The majority of this work was funded as part of a NASA Research Announcement award under Contract \#NNL07AA55C with Craig Hange and Clif Horne as the technical monitors. The authors wish to thank all of the students who have participated in this work so far; their hard work and dedication have been invaluable to this research.

\section{References}

${ }^{1}$ Englar, R. J., "Overview of Circulation Control Pneumatic Aerodynamics: Blown Force and Moment Augmentation and Modification as Applied Primarily to Fixed-Wing Aircraft," Applications of Circulation Control Technology, edited by R. D. Joslin and G. S. Jones, Vol. 214 of Progress in Astronautics and Aeronautics, chap. 2, American Institute of Aeronautics and Astronautics, Inc., 2006, pp. 23-68.

${ }^{2}$ Gaeta, R. J., Englar, R. J., and Blaylock, G., "Aerodynamic Heat Exchanger: A Novel Approach to Radiator Design Using Circulation Control," Applications of Circulation Control Technology, edited by R. D. Joslin and G. S. Jones, Vol. 214 of Progress in Astronautics and Aeronautics, chap. 14, American Institute of Aeronautics and Astronautics, Inc., 2006, pp. 383-398.

${ }^{3}$ Englar, R. J., "Pneumatic Aerodynamic Technology to Improve Performance and Control of Automotive Vehicles," Applications of Circulation Control Technology, edited by R. D. Joslin and G. S. Jones, Vol. 214 of Progress in Astronautics and Aeronautics, chap. 13, American Institute of Aeronautics and Astronautics, Inc., 2006, pp. 357-382.

${ }^{4}$ Englar, R. J., "Application of Advanced Aerodynamic Technolgoy to Ground and Sport Vehicles," 26 $6^{\text {th }}$ AIAA Applied Aerodynamics Conference, AIAA, Honolulu, HI, August 2008, AIAA-2008-6731.

${ }^{5}$ Day, T. R., "Coanda Effect and Circulation Control for Nonaeronautical Applications," Applications of Circulation Control Technology, edited by R. D. Joslin and G. S. Jones, Vol. 214 of Progress in Astronautics and Aeronautics, chap. 24, American Institute of Aeronautics and Astronautics, Inc., 2006, pp. 599-613.

${ }^{6}$ Englar, R. J. and Campbell, B. A., "Pneumatic Channel Wing Powered-Lift Advanced Super-STOL Aircraft," $1^{\text {st }}$ AIAA Flow Control Conference, AIAA, St. Louis, MO, June 2002, AIAA-2002-3275.

${ }^{7}$ Frith, S. P. and Wood, N. J., "Use of Circulation Control for Flight Control," Applications of Circulation Control Technology, edited by R. D. Joslin and G. S. Jones, Vol. 214 of Progress in Astronautics and Aeronautics, chap. 12, American Institute of Aeronautics and Astronautics, Inc., 2006, pp. 337-353.

${ }^{8}$ Angle, II, G., O'Hara, B., Huebsch, W., and Smith, J., "Experimental and Computational Investigation into the Use of the Coanda Effect on the Bell A821201 Airfoil," Applications of Circulation Control Technology, edited by R. D. Joslin and G. S. Jones, Vol. 214 of Progress in Astronautics and Aeronautics, chap. 9, American Institute of Aeronautics and Astronautics, Inc., 2006, pp. $277-291$.

${ }^{9}$ Munro, S. E., Ahuja, K. K., and Englar, R. J., "Noise Reduction Through Circulation Control," Applications of Circulation Control Technology, edited by R. D. Joslin and G. S. Jones, Vol. 214 of Progress in Astronautics and Aeronautics, chap. 6, American Institute of Aeronautics and Astronautics, Inc., 2006, pp. 167-187.

${ }^{10}$ Gaeta, R. J., Englar, R. J., and Avera, M., "Development of Pneumatic Over-the-Wing Powered Lift Technology Part II: Aeroacoustics," 27th AIAA Applied Aerodynamics Conference, AIAA, San Antonio, TX, June 2009, AIAA-2009-3941.

${ }^{11}$ Friedman, C., Jamchi, Z., Yasovitch, S., Arieli, R., and Levy, Y., "Mach Effects On Circulation Control and Jet Flap Airfoils," $26^{\text {th }}$ AIAA Applied Aerodynamics Conference, AIAA, Honolulu, HI, August 2008, AIAA-2008-6716.

12 Jones, G. S., "Pneumatic Flap Performance for a Two-Dimensional Circulation Control Airfoil," Applications of Circulation Control Technology, edited by R. D. Joslin and G. S. Jones, Vol. 214 of Progress in Astronautics and Aeronautics, chap. 7, American Institute of Aeronautics and Astronautics, Inc., 2006, pp. 191-243.

${ }^{13}$ Loth, J. L., "Advantages of Combining BLC Suction with Circulation Control High-Lift Generation," Applications of Circulation Control Technology, edited by R. D. Joslin and G. S. Jones, Vol. 214 of Progress in Astronautics and Aeronautics, chap. 1, American Institute of Aeronautics and Astronautics, Inc., 2006, pp. 3-21.

${ }^{14}$ Imber, R., Rogers, E., and Abramson, J., "Exploratory Investigations of Circulation Control Technology: Overview for Period 1987-2003 at NSWCCD," Applications of Circulation Control Technology, edited by R. D. Joslin and G. S. Jones, Vol. 214 of Progress in Astronautics and Aeronautics, chap. 3, American Institute of Aeronautics and Astronautics, Inc., 2006, pp. 69-102.

${ }^{15}$ Owen, F. K. and Owen, A. K., "Measurement and Analysis of Circulation Control Airfoils," Applications of Circulation Control Technology, edited by R. D. Joslin and G. S. Jones, Vol. 214 of Progress in Astronautics and Aeronautics, chap. 4, American Institute of Aeronautics and Astronautics, Inc., 2006, pp. 105-112.

${ }^{16}$ Cerchie, D., Halfon, E., Hammerich, A., Han, G., Taubert, L., Lucie-Trouve, Varghese, P., and Wygnanski, I., "Some Circulation and Separation Control Experiments," Applications of Circulation Control Technology, edited by R. D. Joslin and G. S. Jones, Vol. 214 of Progress in Astronautics and Aeronautics, chap. 5, American Institute of Aeronautics and Astronautics, Inc., 2006, pp. 113-165.

${ }^{17}$ Alexander, M. G., Anders, S. G., and Johnson, S. K., "Trailing Edge Circuation Control of an Airfoil at Transonic Mach Numbers," Applications of Circulation Control Technology, edited by R. D. Joslin and G. S. Jones, Vol. 214 of Progress in Astronautics and Aeronautics, chap. 8, American Institute of Aeronautics and Astronautics, Inc., 2006, pp. 245-275.

${ }^{18}$ Jones, G. S., Yao, C.-S., and Allan, B. G., "Experimental Investigation of a 2D Supercritical Circulation-Control Airfoil Using Particle Image Velocimetry," $36^{\text {th }}$ Fluid Dynamics Conference, AIAA, San Francisco, CA, June 2006, AIAA-2006-3009. 
${ }^{19}$ Lee-Rausch, E. M., Vatsa, V. N., and Rumsey, C. L., "Computational Analysis of Dual Radius Circulation Control Airfoils," $36^{\text {th }}$ Fluid Dynamics Conference, AIAA, San Francisco, CA, June 2006, AIAA-2006-3012.

${ }^{20}$ Englar, R. J., Jones, G. S., Allan, B. G., and Lin, J. C., "2-D Circulation Control Airfoil Benchmark Experiments Intended for CFD Code Validation," $4^{\text {th }}$ AIAA Aerospace Sciences Meeting and Exhibit, AIAA, Orlando, FL, January 2009 , AIAA-2009-0902.

${ }^{21}$ Pfingsten, K. C. and Radespiel, R., "Experimental and Numerical Investigation of a Circulation Control Airfoil," 4 ${ }^{\text {th }}$ AIAA Aerospace Sciences Meeting and Exhibit, AIAA, Orlando, FL, January 2009, AIAA-2009-0533.

${ }^{22}$ Madugundi, D., Nagib, H., and Kiedaisch, J., "Evaluation of Turbulence Models Through Prediction of Separated Flows with and without Flow Control and Circulation Effects," $46^{\text {th }}$ AIAA Aerospace Sciences Meeting and Exhibit, AIAA, Reno, NV, January 2008, AIAA-2008-0567.

${ }^{23}$ McGowan, G. and Gopalarathnam, A., "Computational Study of Circulation Control Airfoil Using FLUENT," Applications of Circulation Control Technology, edited by R. D. Joslin and G. S. Jones, Vol. 214 of Progress in Astronautics and Aeronautics, chap. 21, American Institute of Aeronautics and Astronautics, Inc., 2006, pp. 539-554.

${ }^{24}$ McGowan, G., Gopalarathnam, A., Xiao, X., and Hassan, H. A., "Role of Turbulence Modeling in Flow Prediction of Circulation Control Airfoils," Applications of Circulation Control Technology, edited by R. D. Joslin and G. S. Jones, Vol. 214 of Progress in Astronautics and Aeronautics, chap. 19, American Institute of Aeronautics and Astronautics, Inc., 2006, pp. 499-510.

${ }^{25}$ Liu, Y., Sankar, L. N., Englar, R. J., Ahuja, K. K., and Gaeta, R. J., "Computational Evaluation of Steady and Pulsed Jet Effects on a Circulation Conrol Airfoil," Applications of Circulation Control Technology, edited by R. D. Joslin and G. S. Jones, Vol. 214 of Progress in Astronautics and Aeronautics, chap. 22, American Institute of Aeronautics and Astronautics, Inc., 2006, pp. 557-577.

${ }^{26}$ Chang, III, P. A., Slomski, J., Marino, T., Ebert, M. P., and Abramson, J., "Full Reynolds-Stress Modeling of Circulation Control Airfoil," Applications of Circulation Control Technology, edited by R. D. Joslin and G. S. Jones, Vol. 214 of Progress in Astronautics and Aeronautics, chap. 17, American Institute of Aeronautics and Astronautics, Inc., 2006, pp. 445-466.

${ }^{27}$ Paterson, E. G. and Baker, W. J., "RANS and Detached-Eddy Simulation of the NCCR Airfoil," Applications of Circulation Control Technology, edited by R. D. Joslin and G. S. Jones, Vol. 214 of Progress in Astronautics and Aeronautics, chap. 16, American Institute of Aeronautics and Astronautics, Inc., 2006, pp. 421-444.

${ }^{28}$ Baker, W. J. and Paterson, E. G., "Simulation of Steady Circulation Control for the General Aviation Circulation Control (GACC) Wing," Applications of Circulation Control Technology, edited by R. D. Joslin and G. S. Jones, Vol. 214 of Progress in Astronautics and Aeronautics, chap. 20, American Institute of Aeronautics and Astronautics, Inc., 2006, pp. 513-537.

${ }^{29}$ Sahu, J., "Time-Accurate Simulations of Synthetic Jet-Based Flow Control for a Spinning Projectile," Applications of Circulation Control Technology, edited by R. D. Joslin and G. S. Jones, Vol. 214 of Progress in Astronautics and Aeronautics, chap. 23, American Institute of Aeronautics and Astronautics, Inc., 2006, pp. 579-596.

${ }^{30}$ Zha, G.-C. and Paxton, C. D., "Novel Flow Control Method for Airfoil Performance Enhancement Using Co-Flow Jet," Applications of Circulation Control Technology, edited by R. D. Joslin and G. S. Jones, Vol. 214 of Progress in Astronautics and Aeronautics, chap. 10, American Institute of Aeronautics and Astronautics, Inc., 2006, pp. 293-314.

${ }^{31}$ McGowan, G., Rumsey, C. L., Swanson, R. C., and Hassan, H. A., "A Three-Dimensional Computational Study of a Circulation Control Wing," $3^{\text {rd }}$ AIAA Flow Control Conference, AIAA, San Francisco, CA, June 2006, AIAA-2006-3677.

${ }^{32}$ Min, B.-Y., Lee, W. J., Englar, R. J., and Sankar, L. N., "Numerical Investigation of Circulation Control Airfoils," $46^{\text {th }} A I A A$ Aerospace Sciences Meeting and Exhibit, AIAA, Reno, NV, January 2008, AIAA-2008-0329.

${ }^{33}$ Fasel, H. F., Gross, A., and Wernz, S., "Investivation of Turbulent Coanda Wall Jets Using DNS and RANS," Applications of Circulation Control Technology, edited by R. D. Joslin and G. S. Jones, Vol. 214 of Progress in Astronautics and Aeronautics, chap. 15, American Institute of Aeronautics and Astronautics, Inc., 2006, pp. 401-420.

${ }^{34}$ Swanson, R. C. and Rumsey, C. L., "Numerical Issues for Circulation Control Calculations," 3rd AIAA Flow Control Conference, AIAA, San Francisco, CA, June 2006, AIAA-2006-2824.

${ }^{35}$ de la Montanya, J. B., Circulation Control and Its Application to Extreme Short Take-Off and Landing Vehicles, Master's thesis, California Polytechnic State University, San Luis Obispo, CA, June 2006.

${ }^{36}$ de la Montanya, J. B. and Marshall, D. D., "Circulation Control and Its Application to Extreme Short Take-Off and Landing Vehicles," 45 ${ }^{\text {th }}$ AIAA Aerospace Sciences Meeting and Exhibit, AIAA, Reno, NV, January 2007, AIAA-2007-1404.

${ }^{37}$ Torenbeek, E., Synthesis of Subsonic Airplane Design, Delft University Press, Delft, The Netherlands, 1982.

${ }^{38}$ Englar, R. J., Smith, M. J., Kelley, S. M., and Rover, R. C., "Development of Circulation Control Technology for Application to Advanced Subsonic Transport Aircraft," 31 ${ }^{\text {st }}$ AIAA Aerospace Sciences Meeting, AIAA, Reno, NV, January 1993, AIAA-93-0644.

${ }^{39}$ Englar, R. J., Smith, M. J., Kelley, S. M., and Rover III, R. C., "Application of Circulation Control to Advanced Subsonic Transport Aircraft, Part I: Airfoil Development," Journal of Aircraft, Vol. 31, No. 5, September-October 1994, pp. 1160-1168.

${ }^{40}$ Federal Aviation Administration, Feneral Aviation Regulation Part 25 - Airworthiness Standards: Transport Category Airplanes.

${ }^{41}$ Alley, N. R., Phillips, W. F., and Spall, R. E., "Minimizing Induced Drag with Blowing Variation along the Span of a Circulation-

Controlled Wing," 45 $5^{\text {th }}$ AIAA Aerospace Sciences Meeting and Exhibit, AIAA, Reno, NV, January 2007, AIAA-2007-0711.

${ }^{42}$ Bobbitt, P. J. and Margason, R., "Analysis of the Take-Off and Landing of Powered-Lift Aircraft," $45^{\text {th }}$ AIAA Aerospace Sciences Meeting and Exhibit, AIAA, Reno, NV, January 2007, AIAA-2007-1256.

${ }^{43}$ Turner, S., Ball, T., and Marshall, D. D., "Gaussian Process Metamodeling Applied to a Circulation Control Wing," $38^{\text {th }}$ AIAA Fluid Dynamics Conference, AIAA, Seattle, WA, June 2008, AIAA-2008-4162.

${ }^{44}$ Turner, S. R., Applied Metamodeling for Aerospace Applications, Master's thesis, California Polytechnic State University, San Luis Obispo, CA, May 2008.

${ }^{45}$ Ball, T., Turner, S., and Marshall, D. D., "Short Takeoff Performance using Circulation Control," $46^{\text {th }}$ AIAA Aerospace Sciences Meeting and Exhibit, AIAA, Reno, NV, January 2008, AIAA-2008-0174.

${ }^{46}$ Ball, T. M., CFD as Applied to the Design Of Short Takeoff and Landing Vehicles Using Circulation Control, Master's thesis, California Polytechnic State University, San Luis Obispo, CA, June 2008.

${ }^{47}$ Waters, M., Anthony, C., McKenzie, G., and Marshall, D. D., "Propulsion System Modeling and Takeoff Distance Calculations for a Powered-Lift Aircraft with Circulation-Control Wing Aerodynamics," $4^{\text {th }}$ AIAA Aerospace Sciences Meeting and Exhibit, AIAA, Orlando, FL, January 2009, AIAA-2009-1258.

${ }^{48}$ Rasmussen, C. E. and Williams, C. K. I., Gaussian Processes for Machine Learning, The MIT Press, Cambridge, MA, 2006.

${ }^{49}$ Robinson, D. F. and Hassan, H. A., "Further Development of the $k-\zeta$ (Enstrophy) Turbulence Closure Model," AIAA Journal, Vol. 36, No. 10, 1998, pp. 1825-1833. 
${ }^{50}$ Krist, S. L., Biedron, R. L., and Rumsey, C. L., "CFL3D User's Manual (Version 5.0)," NASA Technical Memorandum 1998-20844, NASA Langley Research Center, Hampton, VA, June 1998.

${ }^{51}$ Wilcox, D. C., Turbulence Modeling for CFD, DCW Industries, Inc., 3rd ed., 2006.

${ }^{52}$ Spalart, P. R. and Shur, M., "On the Sensitization of Turbulence Models to Rotation and Curvature," Aerospace Science and Technology, Vol. 5, 1997, pp. 297-302.

${ }^{53}$ Swanson, R. C., Rumsey, C. L., and Anders, S. G., "Aspects of Numerical Simulation of Circulation Control Airfoils," Applications of Circulation Control Technology, edited by R. D. Joslin and G. S. Jones, Vol. 214 of Progress in Astronautics and Aeronautics, chap. 18, American Institute of Aeronautics and Astronautics, Inc., 2006, pp. 469-498.

${ }^{54}$ Storm, T. and Marshall, D. D., "Assessing the $\mathrm{v}^{2}$-f Turbulence Models for Circulation Control Applications," $48^{\text {th }}$ AIAA Aerospace Sciences Meeting and Exhibit, AIAA, Orlando, FL, January 2010, AIAA-2010-1054.

${ }^{55}$ Durbin, P. A., "Application of a Near-wall Turbulence Model to Boundary Layers and Heat Transfer," International Journal of Heat and Fluid Flow, Vol. 14, 1993.

${ }^{56}$ Petterson Rief, B. A., "A Nonlinear Constitutive Relationship for the $v^{2}-f$ Model," Annual research briefs, Center for Turbulence Research, 1999.

${ }^{57}$ Petterson Rief, B. A., Durbin, P. A., and Ooi, A., "Modeling Rotational Effects in Eddy-Viscosity Closures," International Journal of Heat and Fluid Flow, Vol. 20, 1999, pp. 563-573.

${ }^{58}$ Golden, R. and Marshall, D. D., "Design and Performance of Circulation Control Flap Systems," $48^{\text {th }}$ AIAA Aerospace Sciences Meeting and Exhibit, AIAA, Orlando, FL, January 2010, AIAA-2010-1053.

${ }^{59}$ Englar, R. J. and Huson, G. C., "Development of Advanced Circulation Control Wing High-Lift Airfoils," AIAA Journal of Aircraft, Vol. 21, No. 7, July 1984, pp. 476-483.

${ }^{60}$ Kulfan, B. M., "A Universal Parametric Geometry Representation Method - "CST"," $45^{\text {th }}$ AIAA Aerospace Sciences Meeting and Exhibit, AIAA, Reno, NV, January 2007, AIAA-2007-0062.

${ }^{61}$ Lane, K. A. and Marshall, D. D., "A Surface Parameterization Method for Airfoil Optimization and High Lift 2D Geometries Utilizing the CST Methodology," 47th AIAA Aerospace Sciences Meeting and Exhibit, AIAA, Orlando, FL, January 2009, AIAA-20091461.

${ }^{62}$ Lane, K. A. and Marshall, D. D., "Inverse Airfoil Design Utilizing CST Parameterization," $48^{\text {th }}$ AIAA Aerospace Sciences Meeting and Exhibit, AIAA, Orlando, FL, January 2010, AIAA-2010-1228.

${ }^{63}$ Englar, R. J., Gaeta, R. J., Lee, W. J., and Leone, V., "Development of Pneumatic Over-the-Wing Powered-Lift Technology; Part

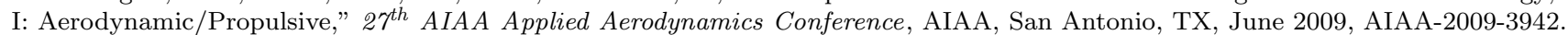

${ }^{64}$ Marcos, J. and Marshall, D. D., "Computational and Experimental Comparison of a Powered Lift, Upper Surface Blowing Configuration," 48 $8^{\text {th }}$ AIAA Aerospace Sciences Meeting and Exhibit, AIAA, Orlando, FL, January 2010, AIAA-2010-0502.

${ }^{65}$ Blessing, B. H., Pham, J., and Marshall, D. D., "Using CFD as a Design Tool on New Innovative Airliner Configurations," $47^{t h}$ AIAA Aerospace Sciences Meeting and Exhibit, AIAA, Orlando, FL, January 2009, AIAA-2009-0045.

${ }^{66}$ Monson, D. J., Mateer, G. G., and Menter, F. R., "Boundary-Layer Transition and Global Skin Friction Measurements," SAE 932550, Society of Automotive Engineers, Costa Mesa, CA, September 1993.

${ }^{67}$ Zilliac, G. G., "The Fringe-Imaging Skin Friction Technique PC Application User's Manual," NASA Technical Memorandum 1999-208794, NASA Ames Research Center, Moffett Field, CA, September 1999.

${ }^{68}$ Naughton, J. W. and Sheplak, M., "Modern Developments in Shear-Stress Measurement," Progress in Aerospace Sciences, Vol. 38, No. 1, 2002, pp. 515-570.

${ }^{69}$ Zilliac, G. G., "Further Developments of the Fringe-Imaging Skin Friction Technique," NASA Technical Memorandum 110425, NASA Ames Research Center, Moffett Field, CA, December 1996.

${ }^{70}$ Driver, D. M. and Drake, A., "Skin-Friction Measurements Using Oil-Film Interferometry in NASA's 11-Foot Transonic Wind Tunnel," AIAA Journal, Vol. 46, No. 10, October 2008, pp. 2401-2407. 